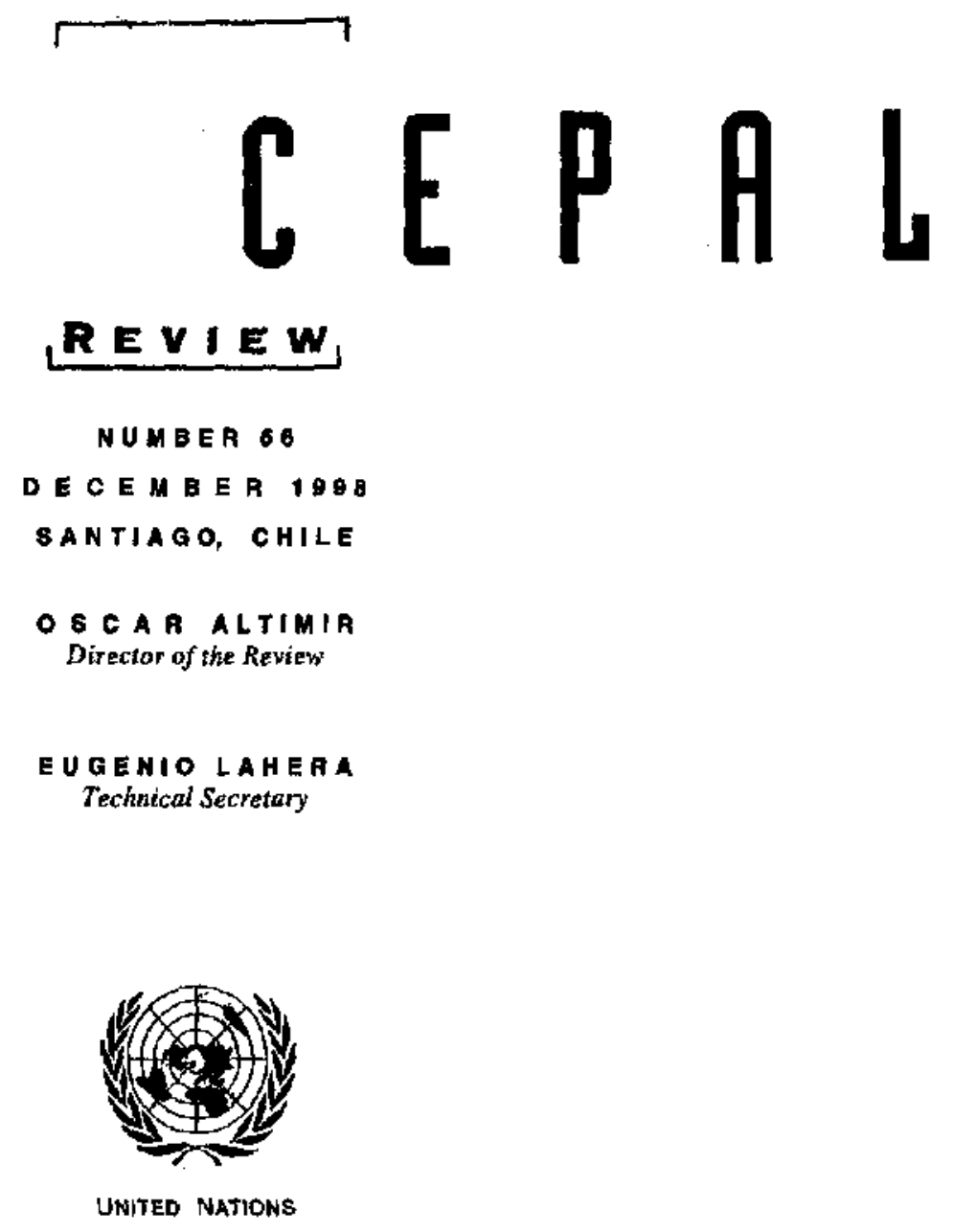


CONTENTS

Beyond the Washington Consensus: an ECLAC perspectlve

José Antonio Ocampo

The Cuban economy

David Ibarra and Jorge Máttar

Education in Latin America: demand and distribution are factors that matter

Nancy Birdsall, Juan Luis Londoño and Lesley O'Connell

Determinants of inequality among urban households

Luis Felipe Jiménez $L$, and Nora Ruedi $A$.

Health management contracts in Costa Alca from a comparative perspective

Ana Sojo

A development strategy tounded on natural resource-based production clusters

Jaseph Ramos

Blg Latin American industrial companies and groups

Celso Garrido and Wilson Peres

Between political control and efflciency gains:

the evolution of agrarian property rights in Mexico

Gustavo Gordillo, Alain de Janvry and Elizabeth Sadoulet

Tariffs and the Plano Real in Brazil

Renaso Baumann, Josefina Rivero and Yohana Zavattiero 


\section{Health management} contracts in

Costa Rica from a

comparative perspective

\section{Ana Sojo}

Social Affairs Officer, Social Development Division, ECLAC.
This article analyses the recent establishment of quasi-markets in the field of public health in Costa Rica through the internal separation within the Costa Rican Social Security Fund of the functions of revenue collection, financing, purchasing and provision of services; the application of a new financing model; and the introduction of management contracts with hospitals and health areas as a key instrument for allocating and transferring resources in accordance with performance and fulfillment of goals. The context and bases of the management reform are examined, and a description is given of both the new financing model and the institutional and organizational implications of the 1997 contracts. These contracts are described in the light of their main thrusts, in which special emphasis is placed on innovations in terms of processes and the development of reliable records of activities, costs and quality, going beyond the mere use of indicators of efficiency and efficacy. The performance of hospitals and health areas in the context of these contracts is described, and finally some views are expressed on the strengths and weaknesses of the relevant institutions and the means of optimizing resource allocation. Throughout the analysis comparisons are made with the experience of Chile. 


\title{
I
}

\section{Introduction}

\begin{abstract}
"Contracts not only provide an explicit framework within which empirical evidence may be derived on forms of organization (so that they are the basic empirical source for proving hypotheses on organization): they also provide clues and pointers on the way in which the parties to an exchange will structure more complex forms of organization". (Douglass North)
\end{abstract}

Since 1996, the Costa Rican Social Security Fund (CCSS) has been promoting the formation of quasimarkets in public health. Without resorting to the establishment of exogenous bodies for this purpose, the new organizational scheme of the coss is designed to separate the functions of revenue collection, financing, purchasing and provision of services at the internal level and to establish a new financing model. The relation between financing, purchasing and the provision of services is seen as a contractual one: management contracts are the key instrument for the allocation and transfer of resources as a function of performance and fulfillment of goals, specifying health objectives and establishing agreed production targets for each centre, at all three levels of attention.

In the following sections, the ambitious management reforms undertaken by the cCss will be analysed first, in the light of their context and bases, after which a description will be given both of the financing model underlying the management contracts and the institutional and organizational implications of the contracts for the year 1997.

The main aspects of the 1997 contracts are described and highlighted, with special emphasis on the fact that the performance measurement which guides them goes beyond the mere use of indicators of efficiency and efficacy, since it assigns an important role to the innovation of processes which should make it possible to systematize the provision of services, shed light on specific aspects of their efficacy, and contribute both to organizational restructuring and to changes in management culture. The importance assigned to the preparation of reliable records on activities, costs and quality and the establishment of information systems which can strengthen management capacity is also highlighted. The contracts also promote the development of an adequate system of referrals and counter-referrals.
An account is given of the performance of the hospitals and health areas under the 1997 contracts in terms of the improvements achieved, the organizational learning process and the main obstacles. In the light of the evaluations made by the CCSS and other elements, some opinions are presented on institutional strengths and weaknesses and on the means of optimizing resource allocation. Finally, some elements which could stand in the way of the process of innovation are mentioned.

Official documentation and interviews and exchanges of ideas with the health authorities and officials who have been involved in the institutional innovation process were the main source for this analysis,' which provides a detailed overview of this particular aspect of the reform process. ${ }^{2}$

In Latin America, ${ }^{3}$ the public health systems of Chile and Costa Rica are the only ones which have established management contracts with public suppliers, thereby progressing through this process of negotiation towards the formation of quasi-markets. This is the reason for the constant comparisons made with the Chilean experience in some aspects. ${ }^{4}$

\footnotetext{
I Among the factors of the greatest importance for the execution of this study were the interest shown by Alvaro Salas, then Executive President of the CCSS, his willing collaboration, and that of the authorities and officials who granted us interviews and facilitated our free access to the documentation (see list of interviewees at the end of this article). The anthor, however, bears sole responsibility for the processing and interpretation of the information provided. ${ }^{2}$ No complete analysis exists in this sespect. For an updated overview of the reform of the Costa Rican health sector in the last four years, in terms of both its direction and execution, see Costa Rica, MIDEPLAN, 1998, pp. 190-220.

${ }^{3}$ In the Caribbean, Trinidad and Tobago has also established separation of functions and annual service agreements.

4 With regard to the context and initial thrust of the introduction of management contracts in Chile, see Sojo (1996b and 1996c). We wish to express our thanks to the Chilean authorities for the interviews granted and the access provided to the documentation on these matters (see list of interviewees).
} 


\section{II}

\section{The context and opportuneness}

\section{of the reforms}

In the 1980 s there was an administrative restructuring on the ccss and an adjustment in its financial base. Although the conflictive delineation of areas of competence between the Ministry of Health and the cCss became a stumbling block for the reform of the Costa Rican health system at that time (Sojo, 1993; Giuendel and Trejos, 1994), growing agreement about the morphology of the system made it possible to clarify their respective areas competence in the mid1990 s.

In 1993, the restructuring of the Ministry of Health was approved and it was made responsible for the functions of general guidance (which need to be further strengthened) and promotion, while the coss was made responsible for operational activities in the field of health in the areas of promotion, prevention, recovery and rehabilitation.

Since 1994, primary attention and preventive activities have been strengthened through Basic Integral Health Attention Teams (EBAIS). The primary health attention activities carried out by the Ministry of Health since the 1970 s were gradually transferred to the CCSS and became part of the model based on those teams, ${ }^{5}$ while the Ministry retained control of three programmes: health promotion and protection, protection and improvement of the human environment, and child nutrition and development. The signing of the management contracts resulted in the transfer of Ministry of Health staff to the CCSS, since the health areas had difficulties in fulfilling their management contracts when the latter were not given effective backing: in one year, from January 1997, 1027 staff members were transferred.

The present reforms in the management of the ccss are taking place at a time when the financial resources of this institution have been placed on a sounder basis at two levels. The ccss provides health services for the population under a system financed

5 For a description of the global thrust of the reforms, see Salas (1996) and Weinstock (1995). For an analysis of the changes made in the health sector in the last four years, see Costa Rica, MIDEPLAN, 1998, pp. 190-211. from compulsory tripartite contributions, with a scheme of universal benefits. The total contribution amounts to $7.5 \%$ of the payroll: the employer pays $4.75 \%$, the worker $2.5 \%$ and the State the remaining $0.25 \%$. The heavy outstanding debt built up by the State with the cCss during decades was negotiated and paid off in 1997. The financial consolidation of the cCss was further strengthened by the 1995 pension reforms, which introduced a pension system run by the CCSS as the exclusive system of pensions payable from the national budget. Within this process, the finances of the health system were also placed on a sounder basis (Sojo, 1997b).

The present reforms in the management of the CCss are an ad hoc initiative designed in the light of a searching self-critical diagnosis ${ }^{6}$ on the characteristics of the ccss as compared with its objectives, and do not form part of a broad exercise on the part of the Costa Rican State in the field of management. Within this area, the most far-reaching policy in this period is the implementation, through some pilot agreements, of the National Evaluation System (SINE), designed and coordinated by MIDEPLAN. The SINE is based on the signing of annual performance agreements -commitments to achieve certain resultsbetween the President of the Republic and the corresponding authorities, endorsed by MIDEPLAN and the Ministry of Finance. The institutional performance matrix specifies the priority programmes and projects, the evaluation indicators, the ranking of each programme, and the institutional commitments entered into in each case (Mora, 1998). The institutions which have fulfilled their targets best have received public praise, but the system has not yet entered on a stage of individual evaluation or rewards.

Other specific initiatives in the area of management have also been carried out, such as the reform of the Customs Service and the coordination and in-

\footnotetext{
6 The arguments underlying the $\operatorname{ccss}^{\dagger} s$ diagnosis of the structoral problems of the institution with regard to management and financing are analysed in section MI.
} 
tegration of the programmes against poverty under the National Anti-poverty Plan.

Unlike anti-State management reform proposals, which see the State as a problem but not as part of the solution (Ferlie, Ashburner, Fitzgerald and Pettigrew, 1996, p. 11), the cCss management reform seeks to maintain and consolidate social and public responsibility for the enjoyment of health as one of the rights of the citizen and to increase its contribution to the systemic competitiveness of the country through better use of resources and greater attention to quality.

These aims are reflected in the guiding principles of the new financing model -solidarity, universality and equity- which became the backbone of the reform of the CCSs as from $1996^{\text {? }}$

The authorities of the ccss saw that there were clear shortcomings in terms of management, but when trying to decide the best timing for the introduction of management contracts they were faced with a dilemma: whether first of all to build up the management capacity needed in order to assign resources in line with performance and then bring in the management contracts (a longer process which might not be practical in political terms) or whether to adopt the system of contracts and learn by experience. This second approach was finally adopted. ${ }^{8}$ Within a short space of time, the central authorities of the ccss formulated an altemative financing model and worked out the features of the contracts, in order to make progress in that direction, with repercussions on the global management of the CCSS. The execution of a pilot plan was begun, and an intensive training programme was put into effect. ${ }^{9}$

It is interesting to reflect on the political factors which have made possible the realization of the reforms in this sector. A reasonable degree of continu-

\footnotetext{
${ }^{7}$ Equity in the distribution of resources is defined as "equal opportunities of access to health services by all users with equal needs" (CCSS, Proyecto de Modernización, 1997a, p. 36).

8 Statements by Alvaro Salas at the interview of 5 February 1998.

${ }^{9}$ We were told that during six months, the authorities and those responsible for the contracts of the bodies providing services had to leave their jobs for this purpose for three or four days a week (interview with Mantique Soto Pacheco, Director of the San Juan de Dios hospital, 5 February 1998). Paradoxically, in some cases the training conflicted with the objectives pursued: according to the 1997 evaluation of hospitals, the fact that those responsible for organizing the process had to leave their work for training activities gave rise to difficulties in following up the contracts.
}

ity has been achieved because the modernization project was begun in the Calderón Fournier administration and was adopted with the unanimous vote of the majority political parties. ${ }^{10}$ This continuity was also aided by the fact that the technical team then responsible for designing the reform of the coss subsequently occupied strategic posts in the Figueres Olsen administration, including the post of Executive President.

The management reform was preceded by discussions on how to improve the use of resources in the field of health; in 1994, for example, a high-level hospital commission was set up. From October to December 1996, meetings and negotiations were held at the behest of the central authorities of the CCSS to decide on the path to be followed in the organization of management contracts. At the start, a number of the actors had negative reactions: for example, the trade unions complained that the idea was to save resources or open up the way for privatization. " Even at the central level of the ccss itself there was and continues to be some doubt about the management contracts, which are seen as a weakening of central action. The hospital directors, who were mostly skeptical to begin with, gradually became more interested, as the expansion of their autonomy would give them more instruments for tackling their problems, and the hospitals which were in a better position to begin the process began to act as leaders. The innovation was actively supported by the Executive, which even took. part in a meeting with hospitat directors ${ }^{12}$ on "quetes" and waiting lists."

\footnotetext{
${ }^{10}$ Statements by Dr. Elias Jimenez, Director of the National Children's Hospital and Executive President of the CCSS from 1990 to 1994, in an interview of 5 February 1998.

II The difficulties in the dialogue about the reforms and some prejudices about them are clearly evident in the analysis and comment session described in GTSS (1997), pp. 4l-70.

12 The proposals made at this meeting cover very varied areas: equipment, systems of giving appointments, more flexible hours of attention, new hiring schemes, decentralization of management, more flexible budgets, expansion of the decision-making capacity of general physicians, purchase of services, improvements in the system of referrals, coordination of services, and absenteeism.

${ }^{13}$ In seeking to understand this political process, the meeting with health authorities called by the Executive President of the cCss on 26 August 1997 was extremely useful. This meeting was attended by Herman Weinstock, Minister of Health; Alyaro Salas, Executive President of the ccss; Femando Matin, Deputy Minister of Health; Julieta Rodriguez, Chief of the Medical Division of the CCSS, and Luis Bernardo Sáenz, Direclor of the CCss modernization project.
} 
An important role was played by the consultancy contract signed with Andersen Consulting and the Hospital Consortium of Catalonia in December 1995 to formulate proposals for prospective budgetary allocation, separation of functions and improvement of quality. At the same time, the ccss modernization team studied and analysed the experiences of the Basque Country, Catalonia, England and Sweden, where the systems are of an eminently public nature in terms of indicators and evaluation schemes

As an illustration of the lessons learned from the analysis of other situations, special mention may be made of the "cultural change" which took place in the Basque Country as a result of management contracts, even though these were not linked with the budget: this experience was incorporated when the Costa Rican initiative was launched in 1997 and is reflected in the relative looseness of the contract requirements.

Awareness of the positive and negative aspects of these experiences also affected three areas of concern in the design of the model: the system of payments should be such as to avoid over-supply of services, or manipulation in conditions of low output; the indicators should not be focused solely on the results, while overlooking the processes, since this would adversely affect commitment and credibility; and the evaluation must be seen as a strong, consistent and constant process. 14

The Chilean management contracts, however, form part of a context which is very different from that of Costa Rica: i.e., a health system whose solidarity had been deeply undermined. Although they were introduced in a period of expansion of expendi- ture in which improvements in efficiency and equity were sought, their framework is a dual health system, both in terms of ownership and of the rationale behind its design. Privatization of the financing and supply of health services, which was introduced under the military regime, promotes the transfer of those with higher incomes from the public to the private system.

So far, this health system is made up of two subsystems which are governed by different rationales and do not compete with each other: the public health insurance is of an unfunded nature and seeks solidarity, whereas the private system operates through individual accounts and risks; consequently, the first system is made up of poor people, and those with high health risks tend to migrate to it, while the second system consists of those with higher incomes and low levels of risk.

This duality inhibits universal coverage of the population and efficient use of resources, militates against a complementary relationship between public and private attention, and significantly limits the capacity for regulation, with serious repercussions in the management area because of the leakage of resources between the two subsystems. 13 The inequalities in health and the cases of inefficiency inherent in the dual model have currently given rise in Chile to a complex discussion on the establishment of a basic, solidary compulsory health insurance scheme of universal coverage which will ensure effective freedom to choose the type of health insurance and supplier of attention in the public and private fields, without any possibility of rejection of patients by the insurance institutions. ${ }^{16}$

\section{III}

\section{A form of resource allocation which makes}

\section{It possible to overcome negative incentives}

Better use of resources, which is the central element in the ccss management reform, is an urgent issue: ${ }^{17}$

14 These details regarding the initial phase of the process were collected on 29 August 1997 at a joint interview with James Cercone, Norma Ayala, Rodrigo Bartels and Mario León, staff members of the CCSS modernizaion project who were responsible for preparing the contracts and have participated in their evaluation. it is maintained that the sustainability of the system is at stake, as expenditure on health has been growing

\footnotetext{
15 With regard to the Chilean case, see Sojo (1996b and 1996c).

${ }^{16}$ For details of the proposals made in this field in a study commissioned by the Ministry of Health, see University of Chile, Department of Economics, 1997.

${ }^{17}$ Unless otherwise specified, the main source of this diagnosis is CCSs, Proyecto de Modernización, 1997a.
} 
TABLE I

Costa Rlca: Selected social indicators

\begin{tabular}{lr}
\hline Indicator & \multicolumn{1}{c}{ Value } \\
\hline Gross montality rate (1996) & 4.12 \\
Infant mortality rate (1996) & $11.83 /_{\infty}$ \\
Life expectancy (1995) & 74.8 \\
Total number of dealhs & 13993 \\
Main causes of death (1996): & 4308 \\
Diseases of the vaso-circulatory system & 2902 \\
Tumours & 1570 \\
$\quad$ Injuries or poisoning & 7.33 \\
Percentage of babies with low weight at birth & 33 \\
Position in the Human Development index (1997) & \\
\hline
\end{tabular}

Sounce: CCSS.

in recent years but its productivity has remained the same or gone down, and the ageing of the population will exert growing pressure on it (table 1). Users are not satisfied, and this leads to double spending on health care when beneficiaries pay extra to obtain private health attention; this phenomenon entails costs in terms of social efficiency and also encourages evasion. It is therefore necessary to control costs and increase efficiency in order to make an effective contribution to the solidarity, equity and competitiveness that the country seeks.

The diagnosis on the management of the ccss finds that control of the ccss budget has been of a primarily administrative nature: the costs of the services provided are not fully known, and systems of billing for services have not yet been developed. It is necessary to change the system of organization and financing based on past allocations in order, instead, to provide resources as a function of efficiency, fulfillment of objectives, and the results and performance achieved in the areas of health attention, finance and quality. Good clinical practices, proper attention to users, and effective coordination among the different levels of health care are considered as criteria of quality.

Within a framework of rigid rules, staff remunerations are determined by seniority, and no account is taken of performance. Although the organization of work is subject to detailed regulations and standard procedures, in the area of clinical activities the professionals act practically without limitations, while the high levels of absenteeism, substitution and "sick leave" exceed the average levels of the country.

Medical specialities form a kind of "captive market" in the hands of the specialists concerned, giving rise to access barriers and long waiting lists, even though there are cases of an obvious shortage of specialists, as for example in ophthalmology, ear, nose and throat specialities and oncology. ${ }^{18}$

It is therefore proposed to establish group or individual incentives to reward merit and the fulfillment of goals and results. However, the use of incentives is seen as a necessary but not of itself sufficient condition for improving the performance of the health system: a further requisite is to develop a new institutional culture guided by costs, output and results, understood as improved levels of health, efficiency and user satisfaction.

\section{IV}

\section{The financing model}

\section{The general concept}

The quasi-market which it is aimed to establish ${ }^{19}$ is based on a new organizational design of the cCSs in which the functions of revenue collection, financing,

\footnotetext{
${ }^{18}$ Interview with Luis Bernardo Sáenz, 26 February 1998.

19 In a quasi-market determined by a contract between a purchaser and suppliers, prices are not set by the interaction of supply and demand and are therefore not free market prices but rather negotiated or managed prices. With regard to demand, the final consumers do not influence the price, which has been regulaled by a government agency. The budgetary limit of that
}

purchasing and provision of health services are separated at the internal level, and on a new financing model. ${ }^{20}$ The relation between financing, purchasing and provision of services is seen as a contractual one: within this framework, management contracts are the

agency, which determines the level of prices that it can offer, is fixed by the government. With regard to supply, in order for the quasi-market to be efficient it is essential that the corresponding suppliers should also be subject to budgetary limits (Bartlett and Le Grand, 1993, pp. 23-24).

20 The main source for the description of the proposed model is CCss, Proyecto de Modemización, $1997 \mathrm{a}$. 
instruments which make it possible to specify health objectives and fix production agreements with each supplier centre, in order to allocate and transfer resources as a function of the latter's performance and fulfillment of goals. In view of this, it was decided that the objectives must be realistic and that the instrument used to achieve them must be adaptable to changing needs and institutional development.

In order to move the central consideration of the management culture from expenditure to cost, it is essential to identify every type of assistance provided to users, both as regards the financier-purchaser relation with the hospital and as regards the exchange of services among the various supplier centers of the cCss. As we will see, this aspect is taken into account in the contracts.

The financing of hospitals and the primary health attention level through a budget based on output, which provides for a maximum amount of resources and a predetermined quantity of services, is reflected in the management contract, which lays down the amount and type of activities which must be carried out

The financing model lays down a variable budgetary component which makes it possible to penalize non-fulfillment of goals, as the availability of resources depends on the objectives and goals. This component amounts to $10 \%$ of the total budget and is divided equally into two funds:

i) the incentives fund, whose resources can be returned to the supplier in order to permit more flexible investment in items that will improve the quality of the services provided and to make it possible to finance monetary and non-monetary incentives for staff members, such as training, improvement and maintenance of physical plant, acquisition of minor equipment, maintenance of equipment, etc. This fund could be increased with the savings generated by management of the production budget, provided these do not run counter to the established objectives and that they do not exceed $80 \%$ of the total savings achieved; and

ii) the solidary compensation fund, which provides a margin of protection or compensation against unforeseen events in budgetary execution, such as output which exceeds the planned level or cost increases.

The introduction of management contracts is envisaged as a gradual process, in view of the limited management capacity of the various suppliers and of the purchaser. In order to achieve greater management capacity, more use should be made of professionals specializing in these activities and of an approach based on the execution of hybrid tasks by doctors, combining a clinical and preventive view in the field of health with knowledge of resource management.

The need for graduality also fits in with the desire to secure a parallel improvement in information systems, since the shortcomings in this area are very great: at the beginning, there was a lack of basic data -such as those on the number of persons attended in each primary level centre and their breakdown by age and sex- both at the level of the local management staff of the centres and at the central level.

\section{Specificationa for the primary level of attention}

The objectives set must be realistic and must be in keeping with the health needs of the population in each Health Area at three leveis: the budgetary level, that of the health objectives, and that of user satisfaction.

The model provides for three phases of innovation in financial matters. In the first of these, the resources corresponding to expenditure on staff costs plus non-personal services are allocated in accordance with the past budget, but an amount of $10 \%$ for variable allocation is introduced.

The resources available from the incentives fund and the solidary compensation fund may be allocated to the following areas, subject to fulfillment of the established commitments: minor investments in machinery and equipment, improvements in buildings, training, scholarships, repair of existing equipment, and other expenditures which improve local problemsolving capacity.

In the second phase, the principle of payment per person attended is introduced: the scales of payment are obtained by dividing the past fixed allocation by the number of inhabitants covered by the services in question. A fund is also set up for improving local problem-solving capacity, to be financed from corresponding reductions in the budgets of the hospitals and to be allocated to primary attention in accordance with its capacity to attract clients and reduce use of the hospitals.

In the third phase, the principle of payment on a per capita basis will be adjusted by the relevant infant 
TABLE 2

Costa Rlca: Values of HPUs, 1997

\begin{tabular}{ll}
\hline Relative scale of value for hospitals, & $\begin{array}{c}\text { Equivalence } \\
\text { in Hospital } \\
\text { by type of activity }\end{array}$ \\
& $\begin{array}{c}\text { Production } \\
\text { Units (HPUs) }\end{array}$ \\
\hline I stay in hospital & 1 \\
I case of emergency attention & 0.35 \\
First visit to a specialist & 0.40 \\
First visit to other medical staff & 0.25 \\
Subsequent visit to a specialist & 0.2 \\
Subsequent visit to other medical staff & 0.1 \\
Visit to a dentist & 0]$. \\
Visit to non-medical staff & 0.05 \\
\hline
\end{tabular}

Source: CCSS

mortakity rates, breakdowns by age and sex, and the corresponding patterns of use of the services. In order to strengthen the system of referrals, the primary level will then receive the resources previously allocated for "first visits" to hospital outpatient departments, while the hospitals will bill the primary attention centres for the patients the latter refer to them.

\section{Specitications for the secondary and tertiary levels of attention}

Management contracts are an instrument which must make it possible to link activities with resources and lay down each hospital's objectives, responsibilities and incentives. In the case of the solidary compensation fund, the resources which are not used will be allocated to a technological renovation programme.

Hospital performance indicators are organized around three groups of objectives: $i)$ those connected with organization, such as recording the referrals made by the primary sector or developing a centralized system for handling waiting lists; ii) those connected with medical matters or specific programmes, designed to solve problems such as reducing waiting lists or reducing the rate of caesareans, and iii) those connected with matters of quality, which are designed to improve the attention provided for users and their level of satisfaction.

In the first phase of financing by output, the overal activities of the hospital are broken down into four areas: hospitalization; ambulatory attention in specialized and non-specialized clinics; emergency attention; and special programmes connected with medical attention, teaching and research. A standard unit of output is defined for the four types of activities. This standard coefficient of equivalence is termed the "hospital production unit" (HPU) and is very closely related with the length of time spent in hospital. The activities of the different areas are grouped together and weighted in a scale of relative values (table 2) which takes account of criteria of cost, planning and productivity and is made up of the values in HPUs.

In this first stage, standard average lengths of stay in hospital are established for each type of section or department, taking into account the seriousness of the cases or the case mix. This incentive rewards hospitals with shorter average lengths of stay than the standard level and serves in general to reduce the average length of stay.

The HPU values are paid in accordance with a scale which remains invariable for the duration of the contract. The production budget is equivalent to the number of HPUs for each activity covered by the contract, multiplied by the corresponding scale of payment. Payment for activities which exceed the agreed number of HPUs will be made in accordance with their marginal cost, and their source of financing -whether savings generated by the institution in question or the solidary compensation fund-varies according to the overall relation between the production budget and the budget actually executed.

It may be noted that the production function for the 1997 contracts was calculated on the basis of 1994 data, and as a level of hospital output greater than that expected was subsequently observed, the scale was modified for the 1998 contracts.

Measurement by HPUs is acknowledged to be an imperfect method, rather insensitive to cost variations and subject to corrections. It is therefore intended to progress towards a system of payment on the basis of the combination of pathologies treated. Consequently, in a second phase the case mix of each hospital will be taken into account in fixing service standards.

In the third phase, in order to establish scales which are in keeping with the complex conditions of the hospitals, financing by HPUs will increasingly give way to the use of the case mix or diagnosis-related groups (DRGs). Subsequently, the standard lengths of hospitalization will be defined by grouping the records of discharges and the scales will be established on the basis of HPUs for discharge groups with clearly identifiable hospitalization episodes. 


\section{Institutional and organizational}

\section{aspects of the contracts}

It would be useful to think of institutions as the rules which shape and limit human interaction by defining incentives applicable to political, social or economic exchanges (North, 1993, p. 13). Paraphrasing that author (ibid., pp. 116,117 and 125), the present period in the evolution of the ccss may be described as a situation of imbalance, in which a new institutional limitation -represented by the management contracts- has altered the traditional structure of incentives, but within the context of rules and conventions which are concomitant with it and continue to be valid, both tendencies being rooted in the action of actors who shape the process of institutional change.

Various types of incentives are therefore conflicting with each other in this transition. And as the new incentives do not possess a satisfactory feedback of information, a suitable organizational structure or effective rules, various specific actions are necessary in order to advance in the desired direction. Some of these have already been described, and in the present section we will highlight those aspects connected with organization. As the market has been described as "a grab bag of institutions, some of which increase its efficiency while others reduce it" (North, 1993), the idea of a mixture is also appropriate when visualizing a quasi-market which is in the process of generation.

Various individual objectives in the ccss innovation process combine to form another more global objective: to change the current supply of services, which has not arisen in response to any real strategy but rather in line with the capacity of each centre to exert pressure. Among these objectives are: to distribute the resources between primary attention and hospital services in a suitable and equitable manner; to consolidate a system of referrals which ensures that services are given at the level corresponding to their degree of complexity, in order to reduce costs; to improve the quality of attention in order to raise users' satisfaction; to reduce waiting lists; to promote efficiency and equity in hospital expenditure, and to expand the use of ambulatory procedures.

The main idea of the reform is that although the coss has fulfilled various functions -purchaser, financier and supplier- these are not delineated in functional, structural and management terms. The central objective is therefore to separate and specialize these functions at the internal level. Management contracts are seen as the main instrument for achieving this separation and progressing towards the main objective of the financier-purchaser: namely, to maximize the amount and quality of health services provided to the population by" making proper use of the available resources.

The ccss currently has a pyramidal and centralized structure, in which the management of investments, maintenance and normative planning is determined at the central level. The regional structures are links between the supplier centers and the central level, carry out instructions received from the centre, and aid in the directorial and management functions of the health establishments in their territorial area.

It is considered that in order to transfer the risks to the suppliers, the supply function must be transferred from the central level of the cCss to the hospitals and Health Areas, in pursuit of greater autonomy in the use of resources and greater responsibility for the results obtained. Such decentralization would mean that the hospitals and Health Areas would assume responsibilities with regard to expenditure, goals and objectives and that the benefits of greater efficiency would likewise be gained by the centres which increase their efficiency. At least initially, it is not planned to decentralize the purchasing function because of the related transaction costs, the low viability of this approach, and uncertainty about the institutional improvements which could be achieved in this way.

It may be noted that there is great interest in decentralization in some hospitals, where it is claimed that the centralization of hospitals has not been a suitable approach, that it has led to inefficient management $^{21}$ and that it has had adverse repercussions in negotiations with pressure groups: whereas previously each hospital negotiated with a trade union which represented only its own staff, negotiations are now at the central level. ${ }^{22}$

\footnotetext{
${ }^{21}$ Interviews with Elf́as Jiménez and Manrique Soto alseady referred to earlier.

22 Interview with Elfas Jiménez already referred wo earlier.
} 
The spheres of competence of the purchaser have been linking up in practice. In order to evaluate the contracts, a special evaluation commission made up of the three management areas of the CCSs was set up and has worked smoothly with the various competent bodies. It should be emphasized that the evaluation process has been closely linked with the execution of the other components of contract implementation; that the evaluation has combined smooth and effective informal coordination within the purchasing body with a highly formal relationship with the supplier units; and that the evaluators have had very direct and prompt access to the higher authorities of the CCss. Another positive aspect which is worth emphasizing is that the various actors involved have made good use of various opportunities, such as meetings and workshops, to negotiate, lobby and settle details of the contracts. ${ }^{23}$

In the administrative division of the CCsS a "purchasing group" has been set up and the negotiation and evaluation components have been strengthened. Guidance of the purchasing function in terms of planning is perhaps the weakest aspect; its development should be aided by the preparation of the Health Plan, with a high degree of participation by the Ministry. The data on output generated by the biomedical in formation section were considered as the official source of information in this respect after the first evaluation workshop of the evaluation unit.

It may be noted that the purchasing function has developed unevenly; more progress has been made in evaluation, whereas there are more lags in the financial aspect. For example the analysis of the contrast between the output-based budget and the historical budget, which should have been carried out during the first year, did not take place, and there are lags in providing methodologies for preparing the medical attention protocols. The hospitals have complained that they lack advisory assistance and support from the central level, especially in informatics, and that the purchasing unit is slow in settling problems or requests which prevent them from fulfilling the contracts. At the same time, however, they say that they have felt well represented in the contracts. ${ }^{24}$

\footnotetext{
${ }^{2.3}$ Interview with Rodrigo Barlels and Norma Ayala, 6 February 1998.

${ }^{24}$ Opinion expressed by Manrique Soto Pacheco at the interview already referred 10 .
}

As the pilot experiment progressed, the internal legal basis for the reforms was also growing stronger. At its meeting No. 7133 on 10 June 1997, the Governing Board of the CCSS approved the conceptual framework of the organizational design (box 1) for the reform of the central level, which is to be carried out with the available human resources and which, in essence, provides for the separation of functions, contractual relations through management contracts, and objectives and general guidelines already contained in the diagnosis summarized earlier.

With regard to the new organizational structure of the Ccss, the Board approved option 23, with certain observations by the members; as shown in figures 1 and 2, the Administrative Division and the Medical Division of the cCSS are given the essential attributions, but the financing function conld be better coordinated. In May 1998, however, the reassignment of personnel and tasks needed to implement the purchasing function was still pending.

Every quasi-market is generated in a given institutional and bistorical context which affects its evolution (Ferlie, Ashburner, Fitzgerald and Pettigrew, 1996, p. 57). In the case of the CCSS, the distinction between functions was carried out by specializing them within the ccss itself, without making outside bodies responsible for some of them. In this quasimarket, the degree of concentration of the purchasing function is monopsonic, since no micro- or meso-purchasers are established. Unlike this monopsonic power, the supply function is deconcentrated into a considerable number of bodies belonging to the CCSS, consisting in 1997 of seven of the 29 hospitals and five of the 46 Health Areas, representing altogether over balf the cCSs budget. For 1998, management contracts were negotiated with 28 health service supply centres: 10 hospitals, 14 Health Areas and 4 cooperatives.

Place of residence is the deciding factor in the allocation of users to suppliers: a system which is also designed to optimize the system of referrals and counter-referrals. There is no question, therefore, of establishing a quasi-market which gives users the possibility of choosing the area or hospital where they wish to be treated, or choosing the doctor they wish to see in the allocated area or hospital.

The purchasing and supply functions, taken together, are concentrated in the Ccss, and the fundamental means of control is the contract; it is precisely this change from hierarchical management to man- 


\section{Box 1}

\section{MAIN LINES OF THE ORGANIZATIONAL DESIGN OF THE CCSS *}

The Costa Rican Social Security Fund is a single unitary organization responsible for providing bealth protection, treating ilinesses and providing pensions under Social Security principles.

Separation of the functions of revenue collection, financing, purchasing and supply of services.

Establishment of a relationship between the financing/purchasing level and the provision of services, based on the fulfillment of management contracts.

Empowerment of units to assume their own management with due authority and responsibility.

Development of a form of organization oriented towards results, user satisfaction and accountability.

Coordinated management of the health service supply centres forming part of a network.

The process of organizational change will be carried out with the available human resources.

Evolution towards a culture of accountability.

Strengthening of the internal and external communication mechanisms, as a means of heightening awareness and publicizing the process of change.

Use of the information systems as key elements in management planning and control.

The new form of organization will facilitate social participation.

Participation of the CCSS staff in the process.

Incentives for productivity and quality.

approved at meeting No. 7133 of the Governing Board, June 1997.

agement by contracts which forms the essence of this quasi-market and, in tum, gives rise to changes in, for example, the systems of information and costs. This quasi-market is inward-oriented and is highly regulated internally by the purchaser, since the central level has powers of regulation, establishment of rules, and appointment of staff to key posts.

Because of the staff recruitment conditions and the rules which exist on conditions of service and employment stability, the central purchasing authority and the supplier units thernselves are still subject to many restrictions. The purchasing of goods and services has been deconcentrated, however, and some Health Areas are allowed to make purchases from third parties: a measure whose efficiency and efficacy has not yet been fully evaluated.

The process also affects the formal and informal power relations within the units supplying services. In the case of the hospitals, this occurs in a context where the traditional autonomy of the staff has even led to problems of intemal governance in some cases. In the national hospitals there are also some party political niches which impede joint organizational work. ${ }^{25}$ In this context, the directors see the contracts as a means for pressuring the hospitals to rase their performance. ${ }^{26}$ It is not easy, however, to transfer the responsibilities of the contract to the heads of medical departments, because of the rapidity of the changes, the limited existing management capacity, and the effect of resistance on the part of the staff. A task which is still outstanding in this respect is to strengthen the hospital directors vis-à-vis their departmental heads. ${ }^{27}$

\footnotetext{
${ }^{25}$ A point raised in the joint interview with Cercone, Ayala, Bartels and Leót already mentioned earlier.

26 Interview with Manrique Soto already mentioned earlier.

${ }^{27}$ Interview with L.B. Stenz on 26 February 1998.
} 
Costa Fican Social Security Fund (CCSS):

Product-oriented joint functional organizational structure

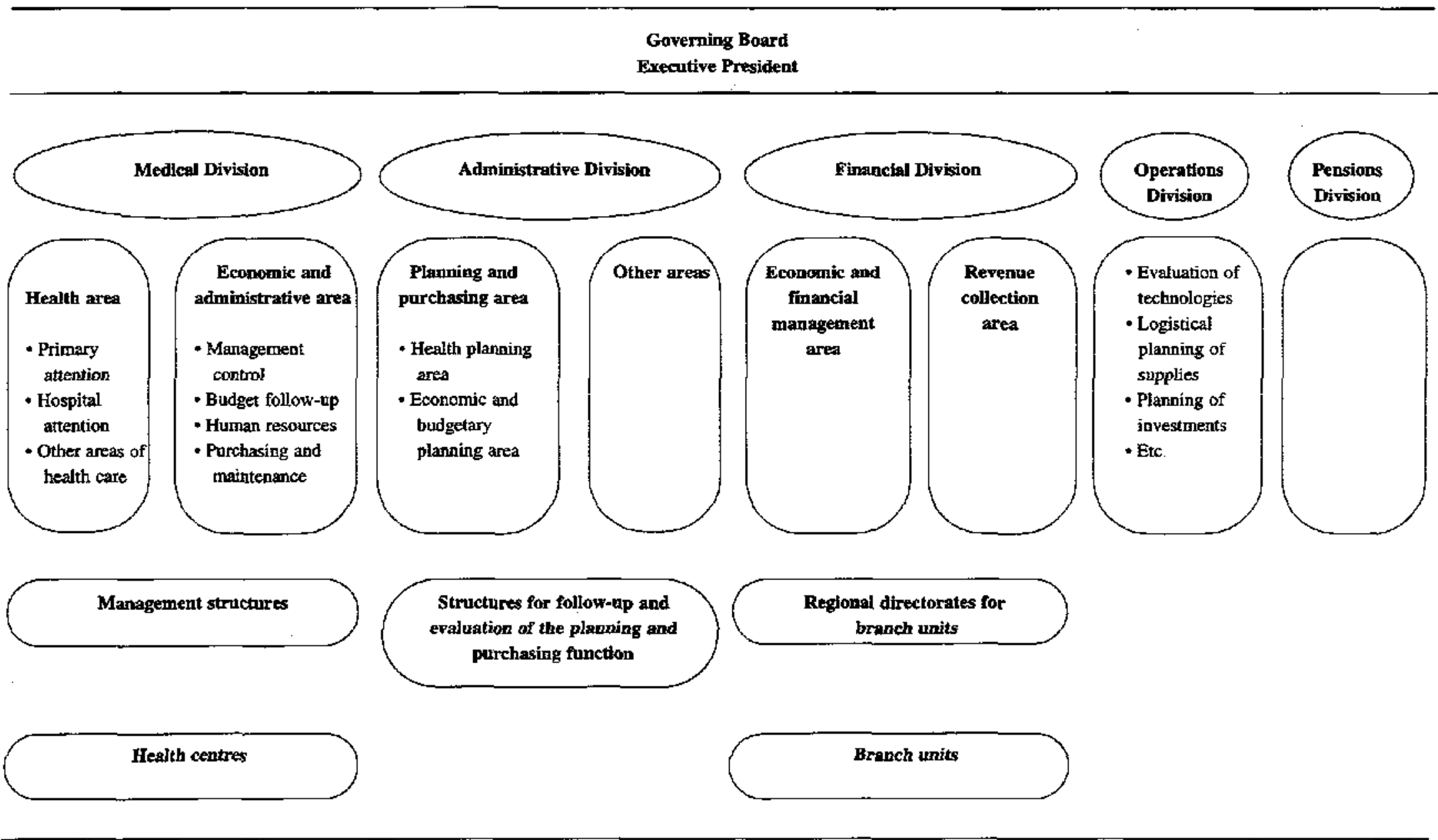

Source: Andersen Consulting/Consorci Hospitalari de Catalunya, by courtesy of the Costa Rican Social Security Fund. 
FIGURE 2

Costa Aican Social Securtty Fund (CCSS): Product-oriented joint functional organlzational structure

(Basic areas of responsibility)

\begin{tabular}{|c|c|c|c|}
\hline & Planning of health services & Purchase of health services & $\begin{array}{l}\text { Managemendadministration of } \\
\text { health service suppliers }\end{array}$ \\
\hline 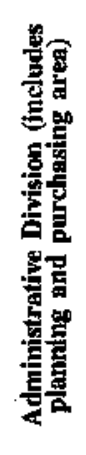 & $\begin{array}{l}\text { - Definition of health care models } \\
\text { - Strategic planning by health objectives (detection and } \\
\text { ranking of health needs) } \\
\text { - Budget preparation } \\
\text { - Evaluation of health results } \\
\text { - Catalogue of health services and content of services } \\
\text { provided } \\
\text { - Institutional control of registration of population covered } \\
\text { - Determination and distribution of economic resources by } \\
\text { territorial areas, population, type of service and levels of } \\
\text { health care } \\
\text { - Planning of opening of new health centres, hospitals, etc. } \\
\text { - Organizarional development } \\
\text { - Communication of process of change }\end{array}$ & $\begin{array}{l}\text { - Aocreditation of suppliers } \\
\text { - Services purchasing portfolio } \\
\text { - Determination and distribution of economic } \\
\text { rescurces by territorial areas, population, type } \\
\text { of service and levels of health care } \\
\text { - Preparation of contracts } \\
\text { - Establishment of guidelines for budget follow-up } \\
\text { - Control of flows of patients and waiting lists } \\
\text { - Follow-up and evaluation of contracts and of } \\
\text { - degroe of satisfaction with services } \\
\text { - Managernent of economic and budgetary flows, } \\
\text { both intertal and with suppliers } \\
\text { - Billing for services } \\
\text { - Attention to users }\end{array}$ & \\
\hline 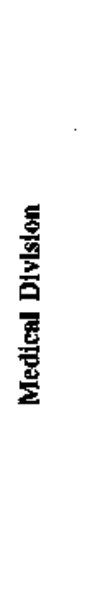 & $\begin{array}{l}\text { - Strategic planning of suppliers } \\
\text { - Evaluation and advisory assistance on policies for } \\
\text { maintenance of centres } \\
\text { - Evaluation of proposals for new technological } \\
\text { investment } \\
\text { - Formulation of policies for purchasing, storage } \\
\text { and distribution of supplies } \\
\text { - Planning of management of human resources of } \\
\text { suppliers } \\
\text { - Establishment of guidelines and training needs for } \\
\text { health personnel, doctors and specialtsts } \\
\text { - Planning of training of health personnel }\end{array}$ & & $\begin{array}{l}\text { - Selection and termination of managers of supplier } \\
\text { centres } \\
\text { - Control of management of supplier centres } \\
\text { - Periodical analysis, in conjunction with the } \\
\text { responsible officials of the management } \\
\text { stnuctures, of the degrce of fulfillment of the } \\
\text { contracts and the necessary corrective policies } \\
\text { - Coordination and management of bealth facilities } \\
\text { - Technical support for the preparation of the } \\
\text { strategic plans of the operational levels } \\
\text { - Technical support for internal organization and } \\
\text { administration of the centres } \\
\text { - Techrical support for the financial management of } \\
\text { the centres } \\
\text { - Human resources management } \\
\text { - Management of purchases and maintenance } \\
\text { - Management of clinical and administrative } \\
\text { information systems } \\
\text { - Organization and execution of training progrannes }\end{array}$ \\
\hline 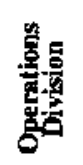 & $\begin{array}{l}\text { - Direction and rechnical coordination of investments } \\
\text { - Establishment of standards of quality, services and health } \\
\text { - Evaluation and authorization of health techoologies and } \\
\text { equipment } \\
\text { - Plazining of corporate jnfornation systems }\end{array}$ & & \\
\hline
\end{tabular}


In Chile, too, efforts are being made to advance in the separation of functions with management contracts. In this respect, the special features of the Chilean health system and the management reforms have given the National Health Fund (FONASA) an important role which has expanded its functions from those of being only a bealth insurance fund to the assumption of purchasing functions within the Ministry of Health system.

In Chile, the aim is to concentrate the function of providing services in the area Health Services and in the hospitals and municipalities linked with them and to take away this function from the Ministry itself: indeed, the continued existence of the Ministry of Health's function as a supplier of services has been mentioned as a serious obstacle in the restructuring of the health system. ${ }^{28}$ In the context that concerns us, this has led to an atomized structure of contracts and of their evaluation. Thus, at the beginning the management contracts were prepared on the basis of proposals by the various units of the Ministry, which also retained their authority in relation with those areas of the contract, so that the corresponding indicators were analysed separately and finally the analysis was integrated in a purely formal manner. For the same reason, the area Health Services had to negotiate the contracts with various organs of the Ministry, termed "special units", which were reduced in 1996 to two -one for the Ministry and one for FONASAand since 1997 to only one, since when the analysis of the contracts is also carried out in a coordinated manner. ${ }^{29}$

It is worth noting that various political decisions which affect the management contracts mean that they are not, of themselves, a goarantee of governance within the health system: a crucial requirement for such governance is to strengthen the incentives and regulations with regard to entry into and continued presence in the system. A notable example in the Chilean experience is the case of a director of a department who flatly refused to sign a contract: efforts were made to persuade him to do so, but there was never any question of his dismissal..$^{30}$

\footnotetext{
${ }^{2 \mathrm{~B}}$ Interview with César Oyarzo, former Director of FONASA, 22 August 1997.

${ }^{29}$ Interview with Pedro Croco, Director of the Management Unit of the Ministry of Health, 3 September 1997.

30 Interyiew with Cesar Oyarzo already refered to earlies.
}

It could be said that the management reforms in the Costa Rican and Chilean health systems have been carried out from the top down, since in both cases the initiative came from the central authorities: the central level of the CCSs, and the Ministry of Health and FONASA, respectively. In both cases, however, the evaluations of the results show the importance of negotiation: the results are better when the contracts are the result of strong rather than weak negotiation, that is to say, when the special local features and preferences are at least reflected in the negotiation of the targets.

The degree of autonomy in the management of resources by the agencies of the CCSS, whether they be hospitals or Health Areas, is still limited; strictly speaking, what has happened is that the past budgets have been adopted and production functions have been prepared on the basis of 1994 data. However, it is planned to relax controls on inputs, that is to say, to relax the restrictions on the use of resources and their allocation to specific areas of expenditure: the contracts contain a clause which simplifies the procedure required for making internal budgetary changes. Traditionally, such changes had to be approved by the Governing Board of the ccss, subject to the authorization of the Comptroller-General of the Republic, which prevented any prompt response to needs.

The institutional morphology of the health sector in Costa Rica favours broad autonomy of suppliers in the use of resources, subject to measures to ensure efficiency and efficacy, because the resources do not come from some central body, such as the Ministry of Finance, but are in the hands of the institution itself and come from the tripartite payment of contributions. What is involved is essentially to decentralize the principal-agent relationship within the CCSs itself. In the case of Chile, this complexity is compounded by the rigidity of the centralized national budgetary system, in spite of some sectoral initiatives designed to facilitate the use of resources and bring in some flexibility by experimenting to some extent with diagnosis-related payments and with payment on a per capita basis (Sojo, 1996c, p. 144).

In Costa Rica, both in the Health Areas and in the hospitals, the level and degree of involvement of the officials engaged in the processes leading up to the preparation of the management contracts and their periodical evaluation have been extremely heterogeneous.

In the CCSS, various processes of negotiation have taken place. Thus, for example, meetings were 
held with clinical groups to define the terminology, criteria, variables, categories and other aspects connected with hospital service production, such as the definition of the major ambulatory surgery programme, first visits by patients to specialists, special ambulatory procedures, treatment involving observation in emergency services, and the redefinition and relocation of the "day medicine" category and problems of standards in gynecology and obstetrics.

Subject to the corresponding limitations -since each body providing services has its own special features - the CCss management contracts open up the way for the establishment of benchmarking of processes and results between Health Areas, on the one hand, and between hospitals on the other. In the areas where the contracts display continuity year by year, obviously the different results obtained in the contracts should make it possible for individual suppliers to establish benchmarks among themselves (even though they will not be fully comparable), for modifying the measurements of performance and making individual goals and objectives more specific or stricter, according to the progress made. The inclusion of clinics run by cooperatives will also be interesting for judging their specific performance and comparing it with that of clinics which belong to the CCSS.

In the medium term, the experience with contracts should make it possible to draw lessons regarding better management practices which may usefully be applied on a more general scale for the reform of the State.

\section{VI}

\section{The 1997 management contracts ${ }^{31}$}

As we have seen, the change from hierarchical management to contract-based management is the main element in the construction of this quasi-market. Consequently, management contracts are suitable elements for reflecting the fundamental features of this reform, which must be considered in all its many dimensions. In the previous section we analysed some organizational aspects connected with the establishment of contracts; in the following paragraphs we will give a detailed description of some features of these instruments and the results of their first year of application.

\section{An overview}

In Chile, the management contracts are established between the central level and the area Health Services (tables 3,4 and 5). Because of the way the suppliers are made up, these bodies establish relationships with the public hospitals and the municipalities and promote the signing of contracts with them. Although the indicators of the Chilean management contracts cover all three levels of attention there is greater emphasis on primary and preventive attention.

In Costa Rica, the cCSS management contracts (tables 6 and 7) are specifically for the Health Areas and for the secondary and tertiary levels of attention.
The contracts (both with the Health Areas and with the hospitals) were initially established from 1 January 1997 to 30 June of the same year and were subsequently renewed up to 31 December 1997 . The good level of fulfillment displayed by the Health Areas led to the establishment of new goals and objectives when their contracts were renewed for the second half year, whereas the delays of the hospitals in fulfilling their commitments (except in the case of the Children's Haspital) caused the deadline for fulfilling the initially agreed goals and objectives to be extended to 31 December.

Within the different varieties of the so-called new public management, a distinction may be drawn between models in which the processes are just as important as the organizational results, and others which are centered more closely on the tasks to be carried out (Ferlie, Ashbumer, Fitzgerald and Pettigrew, 1996, p. 14). The measurement of the fulfillment of the ccss contracts clearly takes the broader view, which goes beyond the mere use of indicators

\footnotetext{
31 The empirical bases for the analysis and interpretation presented in this section were the protocols of the Ccss management contracts and their six -monthly and yearly evaluations, and the protocols of the management contracts of the Ministry of Health of Chile and their annual evaluations.
} 
TABLE 3

Chile: Management contracts with the area Health Services, 1995

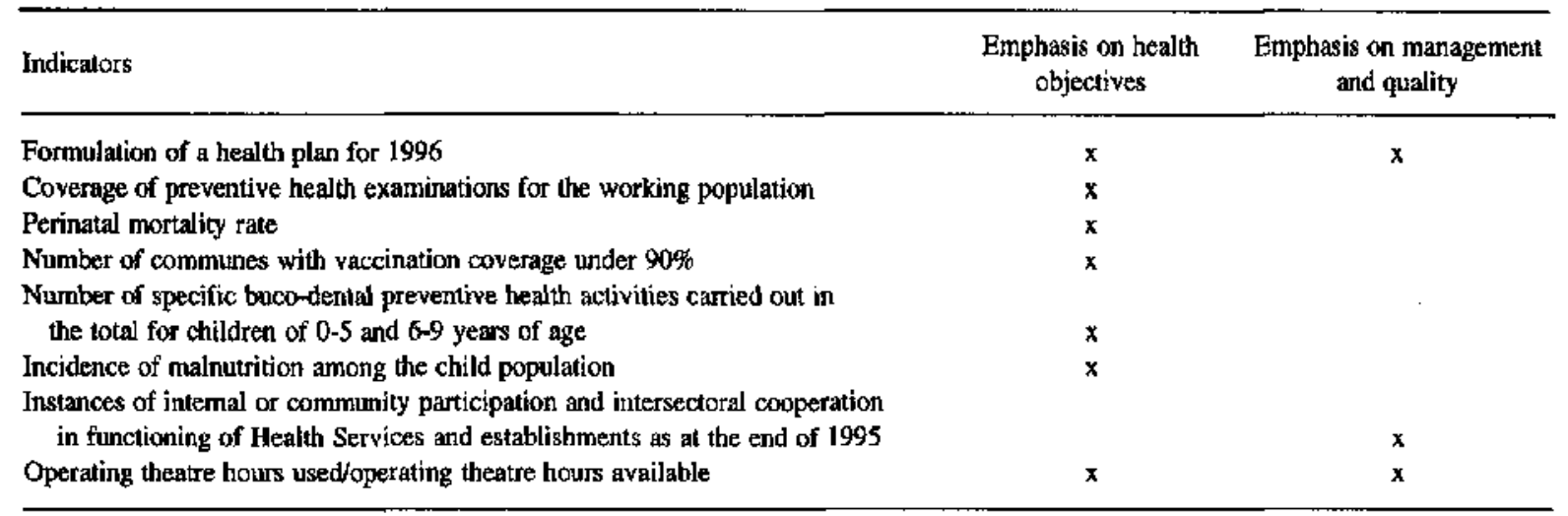

Source: Official documents.

of efficiency or efficacy, atthough obviously these are used too.

Thus, in the broad range of components of the cCss management contracts -including their socalled additional clauses- there are the aims of introm ducing or improving certain information systems, making processes which bad not been functioning properly work and optimizing those which had not been working well, or developing new processes which make it possible to gain a fuller knowledge of the provision of services, put them on a systematic basis, and clarify specific aspects of their efficacy. An analysis of the indicators relating to these aspects shows their great importance both in the Health Areas and in the hospitals, at least in quantitative terms.

Some components, such as the clinical protocols, can help in themselves to further the institutional restructuring, since they involve corresponding changes in working processes. These complementary aspects of the contracts would therefore appear to be at least as important as increases in the indexes of activity and results in the field of health, which are aspects that are obviously also reflected, for example, in the objectives of reducing waiting lists.

Introducing clinical protocols involves technical requirements and agreements on how to record the procedures, with a view to their standardization. In political terms, this has been a complex task which has met with resistance on the part of doctors ${ }^{32}$ or has caused doctors to associate the protocols in their

${ }^{32}$ Interview with Manrique Soto, already referred to earlier. minds with clinical training and progress towards excellence, rather than appreciating their importance for management. The central level has not yet established methodologies for the preparation of protocols, as was planned, but has embarked upon the study of this matter. ${ }^{33}$

The organizational processes have not been given such an important role in the case of Chile, where the contracts do in fact display some weaknesses in terms of the integration of management aspects in the strict sense. In 1995, the indicators in the contracts which were of a strictly management-oriented nature were few in number. Although they were given greater prominence in the following two years, in 1997 the main emphasis was still on the execution of particular health actions connected with indexes of activity (tables 4,5 and 6); in terms of management, the main items that were noteworthy in 1997 were the activities connected with the reduction of waiting lists. The improvement of records as a means of strengthening management capacity has not been taken into account in these contracts.

In Chile, progress has been made in improving the health indicators of the management contracts, which were very weak to start with, and in linking up with ministerial and governmental objectives, especially since 1998 . In this respect, over the course of time the goals and objectives have gradually been made more precise and clearly structured. Their execution, however, which strictly speaking forms the

\footnotetext{
${ }^{33}$ Interview with L.B. Săenz, already referred to earlier.
} 
TABLE 4

Chile: Management contracle with the area Health Services, 1996

(Indicators of activity, by areas)

\begin{tabular}{|c|c|c|}
\hline Health management & $\begin{array}{l}\text { Organizational development and } \\
\text { management of service }\end{array}$ & Quality of attention \\
\hline Coverage of immunization programme & Health plan & Quality management \\
\hline $\begin{array}{l}\text { Implementation of plan of action for } \\
\text { attention to the integral psycho-social } \\
\text { development of childien under six }\end{array}$ & $\begin{array}{l}\text { Diagnosis of efficiency of specialist } \\
\text { clinics }\end{array}$ & $\begin{array}{l}\text { Reduction of intra-hospital } \\
\text { infections }\end{array}$ \\
\hline $\begin{array}{l}\text { Coverage of the preventive health } \\
\text { examinations for adults }\end{array}$ & Efficiency in use of operating theatres & $\begin{array}{l}\text { Index of cesareans as a proportion of } \\
\text { deliveries in type I and II hospitals }\end{array}$ \\
\hline Medico-social evaluation of the elderly & Budgetary munagement of invesiments & \\
\hline $\begin{array}{l}\text { Design and implernentation of a plan of } \\
\text { work to prevent adolescent pregnancies } \\
\text { in the poorest communes }\end{array}$ & Operalional results & \\
\hline $\begin{array}{l}\text { Coverage of Papiunicolau tests for female } \\
\text { benteficiaries between } 25 \text { and } 64\end{array}$ & Maintenance plan & \\
\hline Detection of cases of tuberculosis & Use of equipment and infrastructure & \\
\hline Perinatal mortality & $\begin{array}{l}\text { Reduction of levels of absenteeism on } \\
\text { account of sick leave } \\
\text { Measurement of expenditure on remunerations } \\
\text { Participative management: } \\
\text { Support for municipal management } \\
\text { Internal participation in regular organs } \\
\text { Social participation }\end{array}$ & \\
\hline
\end{tabular}

Source: Official documents.

core of management, has basically been left to the free choice of the area Health Services, since this aspect has not been fully incorporated into the contracts and in the present conditions the monitoring of its progress might be viewed by the Directors of the Services as undue interference. Discussions on health in the country have fundamentally revolved around the policy lines and only marginally around the question of management; when certain adjustments are agreed with the Directors of the Services in order to solve financing problems (generally connected with remuneration), no effort is made to take advantage of the agreed adjustment to request measures at the management level whose fulfillment can actually be verified. ${ }^{34}$

34 This asped of the contracts was noted by Rony Lenz, the Director of FONASA, in an interview on $26 \mathrm{May} 1998$. His references to the weakness of the contracts in terms of management was in response to our critical opinions on this matter, with which he fully agreed.
In Chile, the introduction of diagnosis-related payment has come up against some limitations. This form of financing has not taken the place of the traditional allocation by budget, but has been introduced in a parallel manner on an experimental basis. It was introduced with a high degree of participation at the hospital level, and was therefore not seen as a threat, but it collapsed when an attempt was made to apply it generally, because the diversity of initial conditions and information made it inviable. Its use has therefore been concentrated on specific iterns such as complex treatments and the timeliness of attention, but even so some progress has been made, because the idea of a "package" of services is no longer a concept that gives rise to resistance, and the authorities no longer think solely in terms of isolated services. ${ }^{35}$ Experiences like this highlight the need to

35 These developments with regard to diagnosis-related payments were mentioned to us by Rony Lenz at the interview referred to above. 
TABLE $S$

Chile: Lines of emphasls and indicators of management contracts with the area Health Services, 1997

\begin{tabular}{|c|c|c|c|}
\hline Field of management & Indicators & $\begin{array}{l}\text { Emphasis } \\
\text { on health } \\
\text { objectives }\end{array}$ & $\begin{array}{l}\text { Emphasis on } \\
\text { management } \\
\text { and quality }\end{array}$ \\
\hline Programine management & $\begin{array}{l}\text { Promotion projects } \\
\text { Coverage of adult preventive health examinations } \\
\text { Preventive dental attention for children } \\
\text { Detection of tuberculosis cases } \\
\text { Coverage of Papanicolau testing } \\
\text { Chronic medication under primary health attention } \\
\text { High blookl pressure } \\
\text { Pattem of accreditation of primary health attention } \\
\text { Monibly average number of hours contracted for heads of basic } \\
\text { programmes }\end{array}$ & $\begin{array}{l}x \\
x \\
x \\
x \\
x \\
x \\
x \\
x\end{array}$ & \\
\hline User-oriented managemend & $\begin{array}{l}\text { Modernization projects (article } 10 \text { of the protocol) } \\
\text { Programme on timeliness of attention (article } 11 \text { of the protocol) } \\
\text { Rights of beneficiaries under Law No. } 18.469 \text { (article } 12 \text { of the } \\
\text { protocol) } \\
\text { Reduction of waiting time } \\
\text { Percentage of hospilals with daily visits } \\
\text { Percentage of hospitals with parental care of bospitalized children } \\
\text { Percentage of hospitals with facilities for care of terminal patients } \\
\text { Percentage of hospitals where the father can be present at delivery }\end{array}$ & & $\begin{array}{l}x \\
x \\
x \\
x \\
x \\
x \\
x \\
x\end{array}$ \\
\hline Participative management & $\begin{array}{l}\text { Development Committee } \\
\text { Billing of health services (article } 13 \text { of the protocol) } \\
\text { Indebtediness } \\
\text { Operating results }\end{array}$ & & $\begin{array}{l}\mathbf{x} \\
\mathbf{x} \\
\mathbf{x} \\
\mathbf{x}\end{array}$ \\
\hline $\begin{array}{l}\text { Human resources } \\
\text { management }\end{array}$ & $\begin{array}{l}\text { Absenteeism for sick leave } \\
\text { Performance as a function of expenditure on remunerations }\end{array}$ & & $\begin{array}{l}\mathbf{x} \\
\mathbf{x}\end{array}$ \\
\hline Hospital management & $\begin{array}{l}\text { Management contracts between the area Health Services and the } \\
\text { establishments under their jurisdiction (article } 7 \text { of the protocol) } \\
\text { Use of operating thearte }\end{array}$ & & $\begin{array}{l}x \\
x\end{array}$ \\
\hline Einvirormental management & $\begin{array}{l}\text { Biological and environmental monitoring of enterprises subject to } \\
\text { such control (implementation of D.S. 745) } \\
\text { Water quality } \\
\text { Food poisoning }\end{array}$ & $\begin{array}{l}x \\
x\end{array}$ & \\
\hline
\end{tabular}

Source: Chile, Ministry of Health $(1997 \mathrm{~b})$. The fields in question are defined in the contracts.

consolidate the management area in the modernization of the Chilean health sector, either through contracts with the area Heath Services, or in other ways. In the area of diagnosis-related payments, progress could be made from the point of view of management with the support of processes such as the application of clinical protocols.

The ccss contracts, for their part, establish information systems at a number of levels which should make it possible for both the financier-purchaser and the supplier to know how services are actually being provided and to have the necessary items of information to make a diagnosis on the efficiency and effi- cacy of resource use, to modify the corresponding processes of management and services, and to prepare some indicators of efficiency and efficacy. This range of objectives is behind a number of the additional clauses in the cCss contracts, in which the development of reliabie records on activities, costs and quality occupies a leading place.

Outstanding examples in these terms are the attention and treatment protocols, which should make it possible to gain a knowledge of the processes involved in clinical management; this area has traditionally been a "black box" in which doctors acted without any restrictions. The protocols make it possi- 
ble to modify this degree of autonomy in working practices and should make it possible to scrutinize the way services are provided in order to determine their technical, clinical and management efficiency; to individualize the processes involved in order to progress towards the establishment of cost centres for services provided and begin the application of a system of payment by diagnosis-related groups; to define the responsibilities of staff members and teams in the provision of services, in order to improve quality and verify performance, and finally, to make adjustments in clinical behaviour.

Mention has been made in this respect, for example, of the need to formalize operational guidelines and procedures through protocols, in order to ensure continuity of attention to individual patients, seen as entities who exist over time and have morbidity histories which do not consist of discrete episodes of sickness and should not be dealt with through occasional and fragmentary meetings with different professionals. The "organizational principle" is a form of management of sickness which improves the continuity of attention and reduces the use of unsuitable treatments: it is considered that every illness has a life cycle and an economic structure, and the use of protocols of attention is aimed at forestalling expensive episodes of specific diseases, such as diabetes, and improving the quality of the attention given by making the patient the centre of the process (Bengoa, 1997 , pp. 37 and 38 ).

The ccss contracts incorporate elements designed to improve the organization of the health system and the provision of services, particularly as regards the interaction of the three levels of attention in the system of referrals and counter-referrals: the system of referrals is strengthened by rewarding the capacity of the Health Areas to settle their own problems and reduce the number of referrals, while as regards the hospitals, the system of referrals is regulated and, in some cases, specific mention is made of a hospital network which needs to be consolidated. This would have positive effects on the efficacy and efficiency, coverage and quality of attention (for example, treating diabetic patients whose condition is now stable at less complex levels).

In the Health Areas, the contracts are designed to encourage preventive and health promotion actions at the primary level, which will make it possible in the medium and long term to reduce morbidity and mortality and consolidate desirable health conditions through suitable pre-natal attention; by following up children's development; through early detection of illnesses such as cervical cancer, and through the detection and control of priority chronic diseases such as diabetes and high blood pressure. For the Health Areas, integral standards of attention were prepared for the primary level which form the frame of reference for evaluating its performance.

The consolidation of the system of referrals, with its beneficial effects in terms of the gradual reduction of waiting lines in outpatient and speciality clinics, also depends on advances in other areas of reform of the health sector: namely, the consolidation of the Basic Integral Health Attention Teams. ${ }^{36}$

Interest has recently been displayed in Chile, too, in optimizing the system of the supply of services through the use of management contracts, since previously the links were only between the central level and the individual Health Services. To this end, FONASA has become an intermediary between the area Health Services, which have been reorganized into five zones each covering several such Services, in order to link together the network in the regions. Special "regional units" have been set up to follow up the contracts. 37

Improvement of the quality of attention, seen as an ongoing process, occupies an important place in the cCSS contracts. The measurement of quality is reflected in indicators concerning the efficacy of medical treatments (complications in patients' health, evolution and causes of mortality, etc.) or in procedures for ensuring proper use of medicines, improving individual health records or controlling intra-hospital infections (tables 6 and 7). The concern to raise the levels of quality is also behind measures connected with the timeliness of attention and access to it (reduction of waiting lists, solution of emergencies, and improvement of the efficiency of support services such as pharmacies). In the area of quality, the contracts include measures designed to identify staff processes and responsibilities, such as protocols for washing hands in hospitals. The underlying idea is that the achievement of higher quality can be detected and measured in the processes conditioning it.

\footnotetext{
${ }^{36}$ For a detailed analysis on these teams, see Costa Rica, MIDEPLAN, 1998, pp. 195-200.

${ }^{37}$ Interview with Rony Lenz, already referred to earlier.
} 
TAB1E 6

Costa Rica: Management contracts between the Costa Rican Soclal Security Fund (CCSS) and the hospitals, 1997

\begin{tabular}{|c|c|c|c|c|c|}
\hline Fields & Indicators of information system and processes & Indicators of efficiency & indicators of efficacy & Objectives & Related activities \\
\hline $\begin{array}{l}\text { External } \\
\text { consultations }\end{array}$ & $\begin{array}{l}\text { Centralized systen of appointments for } \\
\text { admission (automated or manual) } \\
\text { Centralized machinery for waiting lists for } \\
\text { specialities (autornated or manual) } \\
\text { Records of diagnoses and treatments made } \\
\text { by each service } \\
\text { System of records of pathologies } \\
\text { Records of procedures }\end{array}$ & $\begin{array}{l}\text { Rate of occupation of } \\
\text { external consultations } \\
\text { Situation with regard to } \\
\text { waiting lists }\end{array}$ & $\begin{array}{l}\text { Mortality rate of patients } \\
\text { treated in multidisci- } \\
\text { plinary clinics }\end{array}$ & $\begin{array}{l}\text { Reduction of waiting lists, } \\
\text { fixing a desired percent- } \\
\text { age and establishing } \\
\text { maximum waiting } \\
\text { times }\end{array}$ & \\
\hline $\begin{array}{l}\text { Hospital } \\
\text { services }\end{array}$ & $\begin{array}{l}\text { New hospital discharge sheet } \\
\text { Records of readrissions } \\
\text { Monthly records of rate of cancellation of } \\
\text { planned surgical operations, with reasonis } \\
\text { Reconds of obstetric attention } \\
\text { Records of activities } \\
\text { Protocol for washing hands in all departments } \\
\text { Protocol for detection and control of intra-tospital } \\
\text { carriers of infectious diseases } \\
\text { Records of obstetric and pediatric attention and } \\
\text { compldcations in such attention }\end{array}$ & $\begin{array}{l}\text { Waiting times for surgical } \\
\text { operations and related } \\
\text { tests, with indicators of } \\
\text { delay } \\
\text { Bed turnover } \\
\text { (over } 60 \text { ) } \\
\text { Lengths of stay in } \\
\text { multidisciplinary clinics }\end{array}$ & $\begin{array}{l}\text { Rate of readmissions, } \\
\text { by pathologies and } \\
\text { departments } \\
\text { Mortality rate of children } \\
\text { Complications in mother } \\
\text { and child area } \\
\text { Complications in different } \\
\text { patients in multidisci- } \\
\text { plinaty cinics } \\
\text { Mortality rate of patients } \\
\text { treated in multidisci- } \\
\text { plinary clinics } \\
\text { Rate of cancellation of } \\
\text { planned surgtcal } \\
\text { operations } \\
\text { Rate of post-delivery } \\
\text { and post-cesarean } \\
\text { complications }\end{array}$ & $\begin{array}{l}\text { Prevention and control of } \\
\text { intra-hospital infections } \\
\text { Quantitative and } \\
\text { qualitative analysis of } \\
\text { complications in the } \\
\text { mother and child health } \\
\text { area, by pathology, age } \\
\text { and period }\end{array}$ & $\begin{array}{l}\text { Designation of staff to be } \\
\text { responsible for coordina- } \\
\text { tion of the respective } \\
\text { activities } \\
\text { Training in prevention and } \\
\text { control of intra-hospital } \\
\text { infections } \\
\text { Detection and control of } \\
\text { intra-hospital carriers } \\
\text { of infectious diseases }\end{array}$ \\
\hline $\begin{array}{l}\text { Systern of } \\
\text { referrals }\end{array}$ & $\begin{array}{l}\text { Records of referrals fromt the primary and secondary } \\
\text { leveis and areas of attraction, in order to identify } \\
\text { patients. Records include territorial location, } \\
\text { reasons, or diagnosis for the referrals } \\
\text { Validity of systems of referrals and counter-referrals } \\
\text { Tripartite report (by the "Grecia", "Monseñor } \\
\text { Sanabria" and "Mexico" hospitals) to the } \\
\text { Financier-Purchaser on pathologies which must } \\
\text { be dealt with at other levels of the systern }\end{array}$ & & & & \\
\hline
\end{tabular}


TABIE 6 (cancleded)

\begin{tabular}{|c|c|c|c|c|}
\hline Fields & Indicators of information system and processes & Indicators of efficiency & Indicators of efficacy & Objectives \\
\hline $\begin{array}{l}\text { Human } \\
\text { Resounces }\end{array}$ & $\begin{array}{l}\text { Records of number of days of sick leave by } \\
\text { CCSS staff and by the population in general }\end{array}$ & . & & $\begin{array}{l}\text { Introduction of a systern of } \\
\text { control and evaluation } \\
\text { of amount of sick leave } \\
\text { Reduction of number of } \\
\text { days of sick leave (\%) } \\
\text { Percentage of upper } \\
\text { management staff } \\
\text { trained in management }\end{array}$ \\
\hline
\end{tabular}

Quality and Surveys of degree ofsatisfaction of outside users

attention to Receipt of written complaints made by users,

nsers with a maximum response time of 10 days

Support $\quad$ Records of issue of medicines

services Report on use of mexilcines

Suitable times of issue Proper use of medicines

Qualitative analysis of

Establishment of a userusers' complaints

oriented programme of

continuous improvement of attention

Programmes of instruction of patients

Systems to avoid over-issuc of medicines

Consolidation of "satellitc" pharmacies

\section{Clinical Protocols of attention}

attention Protocols of treatment

Establishment of commitces on protocols of atention and treatment

Preparation of reports an

protocols of activities

Source: Prepared and classified by the author on the basis of official documents. 


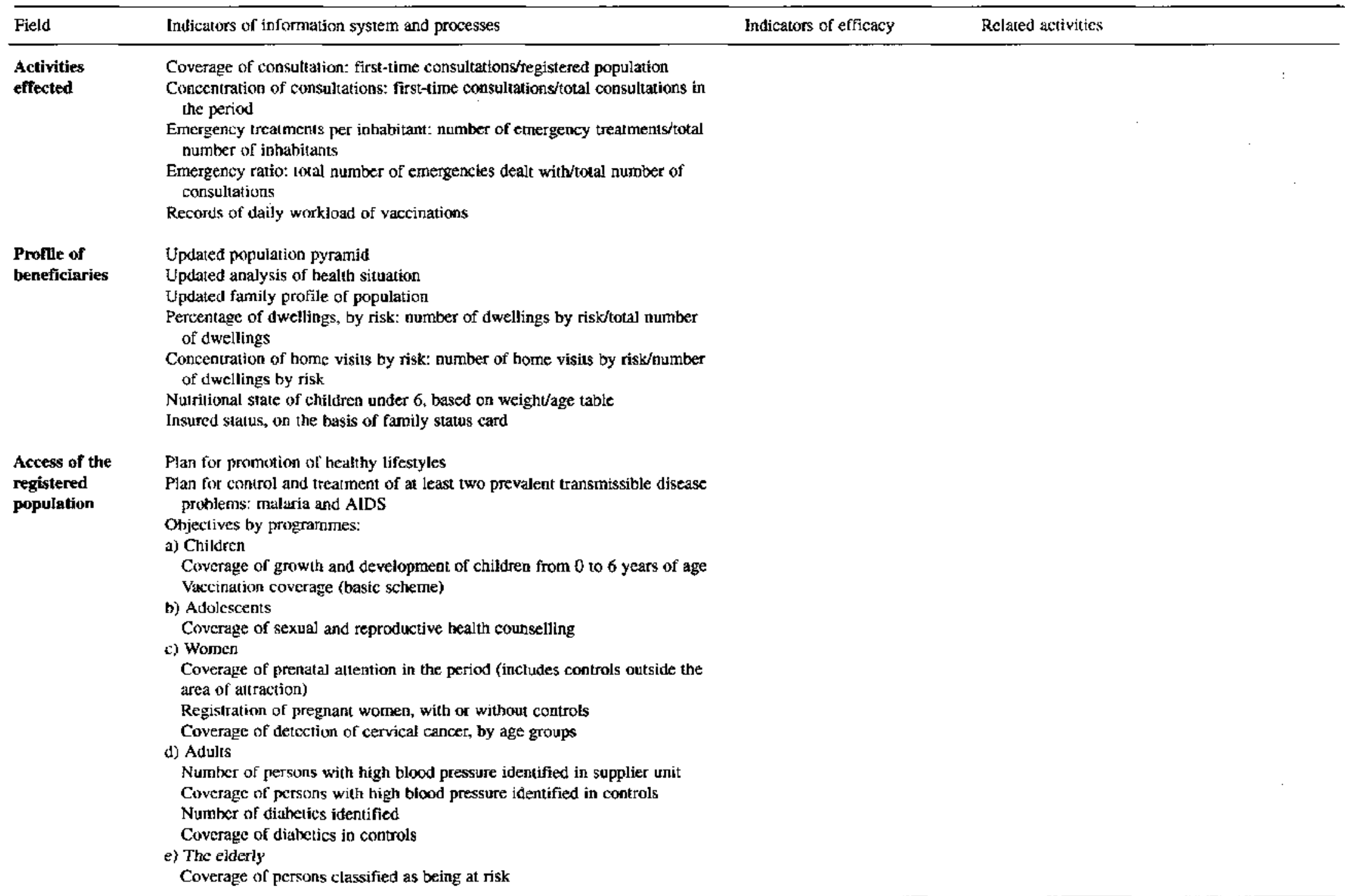


TABLE ? (coscaluded)

\begin{tabular}{|c|c|c|c|}
\hline Field & Indicators of information system and processes & Indicators of efficacy & Retated activities \\
\hline $\begin{array}{l}\text { Strengthening } \\
\text { of system of } \\
\text { referrals }\end{array}$ & $\begin{array}{l}\text { Fulfilment of referrals to a gives hospital } \\
\text { Preparation of proposals on the interlinking of health establishnents and } \\
\text { levels of attention } \\
\text { Coordination with other actors in the area in pursuit of integral atteation } \\
\text { Receipt of counter-referrals from the area } \\
\text { Recording of cases referred to other levels of attention } \\
\text { Activities generated by the Health Area at the following levels of attention: } \\
\text { Records of requests for X-rays } \\
\text { Records of requests for laboratory tests } \\
\text { Records of prescriptions requested }\end{array}$ & $\begin{array}{l}\text { Solution of emergencies: } \\
\text { total number of emergencies } \\
\text { referred to another level } \\
\text { of attention'total number } \\
\text { of emergencies attended } \\
\text { Percentage of referrals: } \\
\text { total number of referrals/total } \\
\text { number of consultations }\end{array}$ & - \\
\hline $\begin{array}{l}\text { Clinical } \\
\text { attention }\end{array}$ & $\begin{array}{l}\text { Individual health records } \\
\text { Complete clinical history and physical examination, with identification } \\
\text { sheet } \\
\text { Records of attention given to patient (clinical records in health or } \\
\text { other record) }\end{array}$ & & $\begin{array}{l}\text { A continuous quality improvement team which } \\
\text { analyses and initiates a plan for providing } \\
\text { sotutions in at least two critical areas of } \\
\text { health services } \\
\text { A commission to analyse deaths of mothers } \\
\text { or children and investigate each case. } \\
\text { A mechanism to control the quality of the } \\
\text { individual health records, with at least } \\
\text { the following requisites: existence of a } \\
\text { responsible person or group and evaluation of } \\
\text { at least one representative sample of health } \\
\text { records during the period of the contract }\end{array}$ \\
\hline $\begin{array}{l}\text { Quality and } \\
\text { attention to users }\end{array}$ & & $\begin{array}{l}\text { A system for receiving users' } \\
\text { cormplaints and suggestions }\end{array}$ & $\begin{array}{l}\text { A readily accessible piace for the reception } \\
\text { of complaints and suggestions; existence of } \\
\text { a staff member or group to deal with, answer } \\
\text { and settle complaints; generation of a list of } \\
\text { leading problems and plans for solving them } \\
\text { Application of the instrument on user satisfac- } \\
\text { tion put forward by the financier-purchases } \\
\text { frformation for users on the services } \\
\text { provided by the centre }\end{array}$ \\
\hline Human resources & $\begin{array}{l}\text { Updated records of the staff, by categories } \\
\text { Records of staff sick leave, by categories }\end{array}$ & & \\
\hline $\begin{array}{l}\text { Strengthening of } \\
\text { cost centres }\end{array}$ & $\begin{array}{l}\text { Gradual development of accounting records different from those tradjitionally } \\
\text { used, with the advisory assistance of the financler-purchaser } \\
\text { Timely submission of financial and accounting data }\end{array}$ & & \\
\hline
\end{tabular}

Source: Prepared and classifice by the author on the basis of official documents. 
To paraphrase Hirschman, sunce this reform cannot be based on the danger that the client may "walk out of the shop", the "users' voice" is taken as the source of feedback. In order to secure this feedback, systems are established which make it possible to determine both the main faults observed in clinical attention and the degree of satisfaction of users, and procedures for dealing with complaints are laid down.

The concern to find out the opinions of users also led to the execution in 1997 of an "Opinion Survey on the cCSS Health Services" which examined the services provided by that organization in each region of the country (EYMSA, Statistics and Marketing, 1997). On a scale from 1 to 10 , the services received an average rating of 8.2 , which was considered good. The service with the best rating was hospitalization, with an average of 8.6, and second place was occupied by the Basic Integral Health Attention Teams, with an average of 8.4 ; both the medical and the para-medical staff were also given good ratings.

The survey brought out some common bottlenecks, however: the aspects considered to represent a serious situation in very varied areas of the country, with ratings of less than 7 points -issue of appointments, hours of attention, rapidity of attention, time needed for the supply of medicines- mainly concern the timeliness of attention, and the ratings are lowest with regard to support services. The survey did not include any questions providing indications of the efficacy of the services provided, such as complications in recovery from sickness.

The contracts in Chile and Costa Rica share some common objectives, such as the reduction of waiting lists for specialist attention, better use of installed capacity -for example, of operating theatresand reduction of absenteeism among doctors. Significantly reducing such absenteeism is one of the most difficult objectives to achieve, however, if the means used is exclusively or primarily the managernent contracts, without any substantial changes in forms of hiring and remuneration of staff (Sojo, 1996c).

Thus, the reduction in rates of absenteeism for sick leave in Chile in 1996 -the first year in which contracts were used- was only significant in some of the area Health Services; in other Services the rates even rose. The next year the same thing happened, and the reductions were only of a minor level, as was to be expected; furthermore, the reductions have not always been maintained in the individial services.

Finally, it is worth noting that in the 1997 contracts of the ccss the Single Incentive Fund was al- most inoperative in the case of hospitals, since no provision had been made for the necessary separation of funds; in 1998, however, this separation was effected, and as from January $0.5 \%$ of the budget was set aside for this purpose, in order to reach a total of $10 \%$ in the year. The Health Areas, in contrast, did receive between $2 \%$ and $4 \%$ from the incentives fund in 1997.3

\section{Performance of the Health Areas}

The evaluation of the additional clauses of the contracts takes account of important contextual aspects of an organizational nature which help in understanding their results. Among these aspects are the nature of the staff assigned as counterparts and their attitude to change; the degree of knowledge of the heads of services and the evaluation team regarding the contracts; the forms of organization of work -for example, internal coordination of services or their atomization- and the use of information throughout the process. Big contrasts have been found in this respect: as in the case of the hospitals, there are shortcomings in the dissemination of the objectives and advances of the contracts and in the commitment of the staff to innovation. It has also been noted how important it is to appoint persons to be personally responsible for the execution of the procedures or tasks included in the contract.

With regard to organizational aspects, the evaluation notes a high degree of commitment and responsibility on the part of the support team and the members of the Basic Integral Health Attention Teams, both in the achievement of the objectives and in making proposals for their fulfillment. Progress was made in the course of the year in overcoming resistance to change, teams for ongoing quality improvement were formed and trained, all the directors and managers were trained in management matters, and healthy lifestyle programmes were implemented, aimed at the population of all the Health Areas. The evaluation considers that in order to motivate the doctors and secure their active participation there must be closer communication between the directors and the support team for the contracts.

An improvement was observed in the level of management over the year thanks to the training processes. Moreover, the strengthening of the evalu-

\footnotetext{
${ }_{3}^{3}$ Interview with Rodrigo Bartels.
} 
ation process has enabled it to be used also as a management tool.

Natmrally, some Health Areas show greater progress than others in fulfilling the contracts. However, the annual evaluation shows that all of them except one complied with the obligatory clauses. With regard to the quality clauses, their degree of fulfillment was satisfactory and this meant that there was partial compliance with the integral attention clause, whose coverage was linked with quality criteria. The records made it possible to collect and verify a great deal of information in the Health Areas, and the information system is gradually being consolidated.

The evaluation expresses some concern over the quality of the medical files, since a considerable number of shortcomings were/observed which seemed to indicate some lack of collaboration on the medical side. Even so, however, there has been progress at this level, and a noteworthy advance has been registered in the application of the established criteria and an improvement in the quality of the services provided by the Basic Integral Health Attention Teams, with the introduction of pre-consultations and an increase in preventive measures which has warranted congratulations from some communities.

With regard to quality, mechanisms have been established for the receipt of complaints and sugges. tions and groups responsible for investigating the cases and preparing replies have been set up; the local commissions to analyse infant mortality have continued the work already begun; the question of quality has been incorporated into the direct attention level through coverage evaluation criteria, and the recording and analysis of information has been promoted as an instrument for improving management. The teams say that they feel moxe consolidated as such, with common goals and concern for the quality of processes. The staff has been trained and educated in improvement of quality and attention to clients. At the same time, management weaknesses have been identified which require advisory assistance assigned by the central level.

In the same field, quality criteria were incorporated in the second half of 1997 in the services provided by the Health Areas, in accordance with the rules on integral attention for each one of the objectives of the contracts. Although it was decided not to take this aspect into account when evaluating fulfillment, very serious work was carried out on it and this made it possible to identify the weaknesses that needed to be corrected and served as a basis for intproving the 1998 contracts, which officially included criteria on service quality. ${ }^{39}$

The Health Areas registered a positive response to the incentives applied during the first half of the year; this was so, for example, in the case of the Pacific Central region.

The system of record cards traditionally used at the primary level of attention in the country had not been very strictly applied in the past. As already noted, when the reform began there was a lack even of basic data such as the population attended in each primary level centre and its breakdown by age and sex. In this sense, the contracts with the Health Areas can also be useful in general for selective social policies of an individual and geographical nature, since the contracts require the individual identification of all the beneficiaries of the services provided by the Health Areas and the preparation of an economic and social profile which makes it possible to establish what the population at risk is. The cards contain information on the geographical location and characteristics of the dwelling, sanitation, and the sex, age, schooling, place of work, insurance status, vital facts, vaccination records and health situation of the persons making up the family nucleus.

\section{The performance of the hosphais}

In some hospitals the introduction of the contracts was preceded by administrative reform measures. With regard to the additional clauses of the contracts, the annual evaluation notes that the main achievements of the hospitals included the reduction of waiting time and waiting lists in all the centres, both in support services and in outpatient departments, emergency departments and hospitalization.

The evaluation also registers better performance as regards the provision of final services in these areas. The advances made in service to the client vary from one hospital to another, but they cover a broad spectrum: internal remodelling of waiting rooms for internal and external users; talks directed to internal users on matters related with the quality of attention to clients; re-ordering of the hours of attention for the public in laboratory and pharmacy services; improvements in the equipment of support services; introduc-

\footnotetext{
${ }^{39}$ Views expressed by Norma Ayala.
} 
tion of new types of facilities to satisfy the needs of special population groups in the area of attraction, and optimization of the use of operating theatres and various services.

The achievements also vary from one hospital to another with regard to organizational aspects and working processes. The evaluation highlights the formation of working teams which have promoted the real participation of workers in the improvement of everyday processes; the formation of support teams for the reform process in all centres; the use of information analysis for taking decisions; the development of automated systems in some centres; the establishment of operational and technical rules and controls for evaluating working processes; better knowledge of the occupational profile of staff members; standardization of working processes, and improvement of records.

With regard to quality, user satisfaction surveys were carried out which made it possible to find out users' needs; teams were formed for the ongoing improvement of quality; medical protocols were designed in all hospitals; intra-hospital infections were controlled and reduced, and complaints and suggestions offices were set up, with special groups responsible for solving complaints and giving answers.

Also at the organizational level, plans and strategies have been prepared for internal and external communication; mass communication media have been used, such as notice boards, sound and newsletters for informing users about the prevention of infections and health education, and the communication between chiefs and subordinates has been improved.

The efforts to measure hospital output made under the terms of the 1997 contracts, however, showed that many unsatisfied requirements prevented satisfactory measurement, so that the output analysis model took on an experimental nature. The evaluation also noted that the model must be adjusted in order to attain the degree of reliability required in order to establish relations of an economic nature between production and financing and in order to make a proper comparison of the production of the different hospital centres. The annual evaluation report has therefore simply given a brief account of aggregate production by activities and has not sought to establish such relations or to effect comparisons between the hospitals concerned. ${ }^{40}$

40 The hospitals which took part were the Calderón Guardia, the México, the Monseñor Sanabria, the National Children's Hospital, the San Juan de Dios, the San Francisco de Asís and the William Allen.
The half-yearly report had already been categorical in these terms: "on the basis of the present production information it has not been possible to establish a budget based on production in any of the hospitals". The annual report is more cautious: the production data are presented as provisional and subject to revision at the request of the centres themselves or the central level.

The evaluation considers that the relative values of the model must be adapted, since their standards are strictly empirical and were assumed on the basis of past operations, which is precisely what the authorities are seeking to change. It also asserts that the methods of analysis must be improved and that the measurements do not therefore reflect the true activities of the centres.

With regard to the records of activities, the main obstacles detected for measuring production are: lack of verification, backing up and validation of the data; information which is not in line with the desired measurement of objectives because it was not provided in a timely manner; dissimilar criteria for the recording, consolidation and format of information, and differences between the reports prepaned to provide information to the central level. As we can see, the shortcomings are related both with the quality of the information and traditional management practices, and with the fact that the contracts accepted the heterogeneity of the information and records. In order to overcome this heterogeneity, the authorities are working on a national information system which, using a common information processing platform, will make it possible to secure compatibility between the systems used in each of the hospitals.

The problems of information referred to clearly show, in the case of Costa Rica, a problem which has already been highlighted with respect to the development of quasi-markets in general: namely, the need to overcome asymmetries of information between the purchaser and the supplier and, ultimately, to establish incentives for suppliers to facilitate or provide the necessary information. The purchaser would thus be protected from possible opportunistic behaviour by suppliers and would have better background information for establishing the contracts (Bartlett and Le Grand, 1993, p. 209).

In the CCSs, the main safeguard adopted in this respect, both for the hospitals and the Health Areas, has been to establish that "anything that is not recorded will be assumed not to exist": in the 1998 
contracts, information is deemed to be the key for obtaining funds. As the information can be manipulated, however, its veracity may be called into question. In 1997, for example, it was discovered that there was an excessive increase in "first consultations" compared with subsequent consultations, which was considered to be due to the greater weight given to such consultations in terms of HPUs.

The effort to measure production has brought to light veritable traditions in institutional culture. For example, only the recording of discharges from hospital, which is deeply rooted in established practice, is fre from the shortcomings in question. In contrast, in the areas of outpatient attention or emergency attention, the information is neither validated nor verified. This confirms that "informal culturally derived limitations will not change immediately in response to changes in the formal rules" (North, 1993, p. 65).

The 1997 evaluation considers that there are problems connected with the failure of the measurement model to define some concepts properly, as in the vague definition and lack of precision of some categories such as special procedures (where the diversity of criteria led to serious discrepancies in measurement) or the final products.

In the discussion on hospital output and services, hospital directors have referred to the existence of technical difficulties for measuring, with the available information, the attention provided in respect of emergency cases, minor surgery and surgical procedures; the need to establish detailed rules regarding the respective systems of measurement and to follow the international classification of diseases in the case of the clinical files; and the need to specify what is meant by readmittance to hospital and to state the possible causes. ${ }^{41}$ In other cases, it has been suggested that the measurement of hospital cutput is viable when a proper seiection is made of a few actions which adequately reflect production, so that it would be desirable to take account of only a few special procedures. ${ }^{42}$

Finally, the evaluation concludes that the measurement of hospital output does not permit suitable comparison of the results or provide the necessary information for prospective budgetary allocation. After having noted all these points, however, it states that "according to the agreed objectives, the established rules and the method applied, the hospitals with management contracts nevertbeless fulfilled what was required of them". Indeed, taking the hospital production units as a whole, the unit with the highest degree of fulfillment achieved a level of $136 \%$ of its goal, while the unit with the lowest degree of fulfillment nevertheless registered $97 \%$.

When we analysed the respective tables of our own accord, we noted that in most of the hospitals there are discrepancies between the agreed HPUs and those actually effected in specific activities, but the differences are very varied and, generally speaking, the deficits in some activities are offset by the surpluses in others. The relation between deficit and surplus activities varies from one unit to another, and comparison of the various units does not show any significant tendency in terms of activities which predominantly registered deficits or surpluses.

\section{VII}

\section{Are the reforms in danger?}

The "screen", a practice which combines medical corruption and a perverse form of medical selection by patients who are willing to pay for it or forced to do so, is an illegal action which consists of the doctor charging the CCSS beneficiary for the treatment (mainly surgical operations) given in public facilities. It is interesting to note, in this respect, that the contracts have provided indications that may help to reveal and quantify these practices. In 1997, for example, it was found in one hospital that $35 \%$ of the high-cost operations were supposed to have origi- nated in the emergency department, where however they were not registered.

We have brought this matter up at this point because, at all events, the far-reaching measures required for doing away with the "screen" have implications for the rules of the game in more general terms. The permanent nature of staff members' contracts, regardless of their performance, a career

4' Interview with Dr. Manrique Soto, already referred to earlies. 42 Interview with Elías Jiménez, already referred to earlier. 
structure which depends on seniority and not on merit, the stipulation that staff must attend 4 to 5 patients per hour, the tortuous nature of the procedures for securing a staff member's dismissal, ${ }^{43}$ and the inability of patients to make any medical choice for themselves form a strait-jacket which makes it impossible to change this situation to any major extent and, in general, impedes the modernization of human resources management in the ccss.

Inflexibility of hiring conditions is undoubtedly a crucial element which can impede management innovations. In Chile, the interested sectors have so far managed, by militant action, to prevent the amendment of law No. 15076 governing the hiring and remuneration of professional bealth service staff. Thus, a novel Bill was presented in 1995 to make the definition of staff rosters more flexible and significantly more decentralized; to add due recognition of performance, merit and efficiency to considerations of mere seniority in career development; to promote the assignment of individual responsibilities; to interlink recognition of individual performance with that of the institution, and to make continued employment in the system subject to competitions. However, this initiative was shelved (Sojo, 1996c).

In this respect, it is worth reflecting about a particular feature of a public health system which stands out in international comparisons as an example of notable equity, efficacy and efficiency: namely, that of Canada. Although Canadian hospitals have a system of budgets, the doctors who work in them do not earn a fixed salary: their wages depend on the number of patients they attend under a system of free choice by patients of any of the doctors on the hospital staff, in accordance with a scale of charges set by each province (White, 1997, p. 44).

\footnotetext{
43 "The possibility of terminating staff members' contracts must be simplified at the national level. At present, the steps that must be fulfilled are due process, appeal, the local commission, and the Central Labour Relations Commission, and this is where the bottleneck lies: an Act of Parliament is required to regulate this aspect, and an effort must be made to unify the form of hiring for all the different sectors". These were some of the challenges referred to by Dr. Jimernez in the interview mentioned earlier.
}

Continued occupation of management posts should also be linked with the achievement of the proposed objectives. The reform makes it indispensable to develop management skills at various levels.

The ccss contracts also aim to improve the information available on the finances of the supplier agents. With regard to financial management in the strict sense, however, the contracts do not provide for instruments, indicators or activities designed to measure costs which would make it possible to advance directly in the measurement of financial and economic performance and impute costs to the products. This lack could be a serious obstacle for the establishment of the desired financing model, and this should be taken into account when formulating future contracts.

Moreover, the contracts do not currently include convincing economic incentives. With regard to the economic incentives fund, mention has already been made of its weakness in generating such incentives in the short term, since the generation of savings which is supposed to provide it with its resources is extremely limited in the current conditions. Furthermore, there has not yet been any decision to allow the fund to be used to grant wage incentives on merit.

It is therefore debated whether it is really desirable to introduce a system of performance incentives, whether it should be of an individual or collective nature -for work groups or specific units of the organization- and whether it fits in with the performance indicators provided by the management contracts. Among the range of possibilities in the case of economic incentives there is the possibility of introducing performance-linked wages. The systematic use of training or the granting of fellowships could also be useful for this purpose.

It is likewise crucial to lay down clear provisions for penalizing both the suppliers, if they do not fulfill the agreements, and the purchaser, if he does not fulfill his tasks of providing support for the contract: such penalties must have a clear legal basis. It is also necessary to coordinate the terms of the contracts with the execution of traditional auditing exercises, which must be modified in the light of the new distinction of functions and their interrelations.

As noted in the evaluation exercises, it is essential that staff members should know the results of the contracts so that, since they are participants in their strengths and weaknesses, they can collaborate 
in the formulation of strategies for tacking problems and improving quality day by day, in order to avoid discouragement.

At the same time, in spite of all the asymmetries of information facing users and the restrictions on the sovereignty of the consumer typical of the health sector, when forming coalitions which seek excellence in the provision of health services the users are very important, as a source of external pressure on suppliers and of signals which will help in "fixing prices" in the quasi-market from the demand side. This explains the importance of receiving, processing and responding in a timely and suitable manner to the opinions and complaints of clients, collected through the contracts and other means. Consolidating improvements in attention -for example, reducing waiting lines and waiting lists- would undoubtedly bring about greater citizen support for the contracts, which would be very positive for the purposes set forth above.

Another tem which is important in this context is community participation. In the case of the hospitals, Hospital Councils, which are foreshadowed in the recently established Health Councils, will be of fundamental importance. These Health Councils are of an advisory and community liaison nature and consist of seven persons: a representative of the cCss, a representative of the municipality, and five representatives of community or service associations. ${ }^{44}$

The success of the contracts will not depend only on the formal reorganization of the purchaser- supplier rejationship. It will also be necessary to consider how to modify the informal standards and rules which come to take on a binding nature and will be determined by the changes in the informal power relations, also defining the results. ${ }^{45}$

The development of quasi-markets is rooted in social and institutional relations (Ferlie, Ashbumer, Fitzgerald and Pettigrew, 1996). In considering the long-term effect of the introduction of contracts on the organizational patterns and intez-organizational behaviour of health quasi-markets, particular importance is assumed by the professional networks of medical and paramedical staff and the weight and influence acquired by their management segment, since these professions had traditionally enjoyed a large measure of self-regulation.

The challenge is of vast extent: it consists no less than of harnessing the will of politicians, staff members and the citizens at large in support of a commitment to excellence in the CCSS which will place the country in a promising position on the eve of the new century.

(Original: Spanish)

\footnotetext{
44 Advocates of maximum decentralization of the suppliers, like Dr. Jiménez, consider that these Councils should be given sufficient authority to become Governing Boards of each hospital, while the Central Governing Board, because of its political nature, should lay down general policies and establish the budgetary limits (interview referted to earlier).

45 We thus take account of the warning given by Douglass North: "... although explicit rules provide us with a basic source of empirical materials by which we can test the performance
}

of economies in different conditions, the extent to which these rules have a single, invariable selation with performance is only limited. In other wotds, there is also a mixture of informal standards, rules and characteristics of a binding nature which simultaneously define both the range of choices and the results in terms of success. Conseguently, if we only take account of the formal rules we will have an inadequate and often mistaken notion of the relation between formal limitations and performance ${ }^{n}$. 


\section{Interviews}

On the experience of Costa Rica in health system reform ${ }^{46}$ (held in San José, Costa Rica)

Norma Ayala, staff member of the CCSS Modernization Project, 29 August 1997 and 6 February 1998.

Rodrigo Bartels, staff member of the CCSS Mocernization Project, 29 August 1997 and 6 February 1998.

Adolfo Cartín, General Manager of the San Juan de Dios Hospital, 5 February 1998.

James Cercone, staff member of the CCSS Modernization Project, 29 August 1997.

Elías Jimenez, Director-General of the National Children's Hospital, 5 February 1998.

Mario León, staff member of the CCSS Modernization Project, 29 August 1997.

Fernando Marín, Deputy Minister of Health, 26 Aurgust 1997.

Luis Bernardo Sáenz, Director of the CCSS Modernization Project, 26 August 1997 and 26 February 1998.

Alvaro Salas, Executive President of the CCSS, 26 August 1997 and 5 February 1998.

Manrique Soto Pacheco, Director-General of the San Juan de Dios Hospital, 5 February 1998.

Julieta Rodríguez, Manager of the Medical Division of the CCSS, 26 August 1997.

Herman Weinstock, Minister of Health,

26 August 1997.

On the experience of Chile in health system reform (held in Santiago, Chile)

Pedro Croco, Director, Management Unit, Ministry of Health, 3 September 1997.

Rony Lenz, Director of the National Health Fund (FONASA), 26 May 1998.

César Oyarzo, former Director of FONASA, 22 August 1997.

46 The posts indicated are those which the interviewees occupied at the time of the interview. 


\section{Bibliography}

Bartlett, W. and J. Le Grand (1993): The theory of quasimarkets, in J. Le Grand and W. Bartlett, Quasimarkets and Social Policy, London, Macmillan,

Bengoa, R. (1997): Tendencias recientes y reformas de los sistemas de saiud: mercados internos, competencia gestionada y los sistemas integrados de salud. paper presented at the Seminar on reform of the health sector in Costa Rica, its political viability and its financial sustainability, San José, World Bank, Economic Development Institute (EDr)/Costa Rica, Ministry of Health/Costa Rican Social Security Fund (CCSS), mimeo.

CCSS (Costa Rican Social Security Fund) (1996a): Compromiso de gestión Hospital William Allen y Area de salud Turrialba-Jiménez. Año 1997, San José, December.

$-(1996 \mathrm{~b})$ : Compromiso de gestion cCss, Area de salud de Chacarita. Año 1997, San José, December.

-(1996c): Compromiso de gestión Hospital México, San José, December.

- (1997): Evaluación del compromiso de gestión. Diseño e implantación de mecanismo de asignación de recursos para la modemización de los procesos críticos de las gerencias financiera y médica, San José, 30 May.

-(1998a): Evaluación de los compromisos de gestión de hospitales. Clausulas adicionales. II semestre de 1997, San José, March.

-(1998b): Evaluación de los compromisos de gestión de las áreas de salud. Cláusulas adicionales. II semestre de 1997, San José, March.

-(undated): Definición de indicadores de evaluación. Objetivos especificas. Compromisos de gestión. Hospitales nacionales. I semestre de 1997, San José.

-_undated): Definición de indicadores de evaluación. Objetivos especificos. Compromisos de gestión. Hospitales periféricos. I semestre de 1997, San José.

-(undated): Definición de indicadores de evaluación. Compromisos de gestion Nivel Central. I semestre de 1997, San José.

- (undated): Criterios para seleccionar áreas de salud y hospitales. Compromisos de gestión, 1998, San José, Genencia de División Médica/Gerencia de División Administrativa.

- (undated): Proyecto de modernización. Proyecto gestión de listas de espera en las servicios de salud. Planteamiento de objetivos y subobjetivos, San José.

$\longrightarrow$ (undated): Definición de indicadores de evaluación de los compromisos de gestión areas de salud. I semestre de 1997, San José, Unidad de Evaluacion Compromisos de Gestión.
CCSS (Costa Rican Social Security Fund), Proyecto de Modernización (1997a): Hacia un nuevo sistema de asignación de recursos, San Jose, March.

(1997b): Evaluación I semestre. Compromisos de gestion. Clausulas adicionales hospitales nacionales, San Jose.

- (1997c): Informe de avance, compromisos de unidades del nivel central, San Jose.

-(1997d): Evaluación I semestre, compromisos de gestión nivel central, San José.

CCSS (Costa Rican Social Security Fund), Presidencia Ejecutiva/Gerencias de División (1997): Programa institucional de mejoramiento continuo de la calidad, San José, May.

cCsS (Costa Rican Sacial Security Fund), Junta Directiva (1997): Resolución adoptada por la Junta Directiva en articulo No. 4 de la sesión 7l73, del 10 de junio de 1997, respecto de la transformación del nivel central de la Caja y propuesta para su ordenamiento, San José, June.

CCSS (Costa Rican Social Security Fund), Dirección Técnica de Servicios de Salud, Sección de Investigación de Servicios de Salud (1997): Análisis de la producción hospitalaria de los hospitales con compromiso de gestión. Informe del I semestre de 1997, San José, September.

- (1998): Analisis de la producción hospitalaria de los hospitales con compromiso de gestión. Informe anual 1997, San José, March.

CCSS (Costa Rican Social Security Fund), Proyecto de Modernización, Grupo de evaluación compromisos de gestion. Áreas de salud (1997a); Evaluación de los compromisos de gestión de las areas de salud. I trimestre de 1997, San José.

-(1997b): Evaluación de los compromisos de gestión de las areas de salud. $I$ semestre de 1997, San José.

Chile, Ministry of Health (1997a): Compromisos de gestion 1996. Informe final, Santiago, Chile, April.

-(1997b): Primer informe cuatrimestral. Monitoreo de compromisos de gestion 1997, Santiago, Chile, July.

Costa Rica, MIDEPLAN (Ministry of Planning and Economic Policy) (1998): Gobernando en tiempos de cambio. La Administración Figueres OLen, San José, April.

EYMSA, Estadística y Mercadeo (1997): Encuesta de opinión de los servicios de salud de la CCSS 1997, San José de Costa Rica.

Ferlie, E, L. Ashburner, L. Fitzgerald and A. Pettigrew (1996): The New Public Management in Action, Oxford, U. K., Oxford University Press.

GTSS (Grupo de Trabajo sobre el Sector Salud) (1997): Actas de Seminario-Taller "Hacía un política de 
Estado en salud", San José, Ciudad Universitaria Rodrigo Facio, Facultad de Medicina, July, mimeo.

Güendel, L. and J. D. Trejos (1994): Reformas recientes en el sector salud de Costa Rica, "Reformas de política pública" series, No. 18, Santiago, Chile, Economic Commission for Latin America and the Caribbean (ECLAC).

INVERTEC (1998): Propuesta de consultoría, Sistema de incentivos por desemperio. Proyecto de reforma en salud, January, mimeo.

Mora, M. (1998): Hacia una cultura institucional basada en el rendimiento de cuentas: el caso de Costa Rica, in ECLAC, Taller sobre evaluación de la gestión del gasto público. Compendio de documentos, Santiago, Chile.

North, D. C. (1993): Instituciones, cambio institucional $y$ desempeño económico, Mexico City, Fondo de Cultura Económica (FCE).

Salas, A. (1996): Costa Rica: una reforma dentro del sistema de salud vigente, in I. Jaramillo, C. Molina and A. Salas, Las reformas sociales en acción: salud, "Políticas sociales" series, No. 15, Santiago, Chile, ECLAC.

Sojo, A. (1993): La política social en Costa Rica: panorama de sus reformas recientes, "Reformas de política pública" series, No. 17, Santiago, Chile, ECLAC.

(1996a): La polftica social frente al ajuste $y$ al incremento de la productividad en América Latina y el Caribe, Situación, No. 1, Bilbao, Servicio de Estudios Banco Bilbao Vizcaya.

- (1996b): Reformas de gestion en la salud pública en Chile, "Políticas sociales" series, No. 13, Santiago. Chile, ECLAC. (1996c): Potential and limits of health management reform in Chile, CEPAL Review, No. 59, LC/G.1931P, Santiago, Chile, ECLAC.

- (1997a): La reforma finisecular del sector salud en América Latina y el Caribe: su derrotero e instrumentos, in UNICEF (United Nations Children's Fund/Costa Rica, Ministry of Health, Costa Rica. Las politicas de salud en al umbral de la reforma, "Políticas sociales" series, No. 1, San José.

-(1997b) Los seguros sociales en América Latina y el Caribe ante la reforma del sector salud, paper presented at the Joint Seminar of the Inter-American Conference on Social Security and the Pan-American Health Organization (PAHO) on social security reform processes in the field of health, Mexico City, July, mimeo.

University of Chile, Department of Bconomics (1997): Estudio técnico de la reforma de la seguridad social en salud. La propuesta. Informe final, Santiago, Chile, May, mimeo.

Weinstock, H. (1995): El proceso de reforma del sector salud en Costa Rica, paper presented at the PaneV Forum on Health in the Chilean Development Process, Santiago, Chile, Ministry of Health/Asociación de is. APREs de Chile, October, mimeo.

White, J. (1997): A Comparative Study of Health Care Policy in the United States and Canada: What Policymakers in Latin America Might and Might Not Leam From Their Neighbors to the North, "Financiamiento del desarrollo" series, No. 52, Santiago, Chile, ECLAC, 